\title{
The message from the World Asthma Meeting
}

\author{
P.J. Sterk, S.A. Buist, A.J. Woolcock, G.B. Marks, T.A.E. Platts-Mills, E. von Mutius, J. Bousquet, \\ A.J. Frew, R.A. Pauwels, N. Aït-Khaled, S.L. Hill, M.R. Partridge \\ The Working Groups of the World Asthma Meeting, held in Barcelona, Spain, \\ December 9-13, 1998.
}

\begin{abstract}
The message from the World Asthma Meeting. P.J. Sterk, S.A. Buist, A.J. Woolcock, G.B. Marks, T.A.E. Platts-Mills, E.von Mutius, J. Bousquet, A.J. Frew, R.A. Pauwels, N. AïtKhaled, S.L. Hill, M.R. Partridge. (C)ER Journals Ltd 1999.

ABSTRACT: The 1998 World Asthma Meeting (WAM) has been the first multidisciplinary event aimed to consider asthma as a global public health problem in children and adults. The purpose of the meeting was to present state-of-the-art scientific information and to make recommendations on the research agenda for the coming years.

Five Working Groups of invited experts were appointed to pin-point the established knowledge and the important questions in the areas of epidemiology, prevention, pathogenesis, management, and education. Their reports were discussed during the final plenary session, and are forming the current proceedings of the meeting.

The message of the World Asthma Meeting provides a research agenda supported by the major international bodies involved in this disease. An integrated approach is considered to be essential in order to improve the prevention and care of asthma in all countries of the world.
\end{abstract}

Eur Respir J 1999; 14: 1435-1453.

\begin{abstract}
Correspondence: P.J. Sterk, Dept. of Pulmonology, C2-P, Leiden University Medical Center, P.O. Box 9600, NL-2300 RC Leiden, The Netherlands. Fax: 31 715154691
\end{abstract}

Keywords: Asthma

epidemiology

management

pathogenesis

prevention

therapy

Received: September 161999

Accepted after revision September 201999
During the past decade, it has been increasingly recognized that bronchial asthma is a disease that affects the international community without frontiers. It is a growing public health problem of children and adults in many countries around the world, and the reasons for its highly variable and increasing prevalence are still poorly understood. Following the successful international meeting "Asthma 1995" in Chicago, USA, it was felt that the scientific and medical approach of this disease required a broader basis with input from high- as well as low-income countries. There is no doubt that only by recognizing the similarities and discrepancies of asthma between the various regions of the world, will the fight against this widespread disease be won. That is why six international societies, The European Respiratory Society (ERS), The American Academy of Allergy, Asthma and Immunology (AAAAI), American Thoracic Society (ATS), The European Academy of Allergology and Clinical Immunology (EAACI), The International Union Against Tuberculosis and Lung Diseases (IUATLD), The Global Initiative for Asthma (GINA), (including the National Heart, Lung and Blood Institute (NHLBI) and theWorld Health Organisation(WHO)), endorsed by seven supporting societies (Associación Latinoamericana de Thórax (ALAT), Asian Pacific Society of Respirology (APSR), European Federation of Asthma and Allergy Associations (EFA), International Pediatric Respiratory and Allergy Forum (IPRAF), International Study of Asthma and Allergies in Childhood (ISAAC), International Society for Aerosols in Medicine (ISAM), United Nations Environment Programme (UN-
EP)) decided to organize the first global event, fully devoted to the science and care of asthma. It brought together around 3,000 basic and clinical scientists, nurses, practising doctors, health care professionals and representatives from patient organizations, medical associations and governmental institutions. They exchanged their latest knowledge during a 3.5 days programme, and most importantly, also tried to formulate the most urgent questions regarding the causes and care of this illness in a truly integrated approach.

Regarding the latter, five Working Groups of $\sim 20-25$ delegates each were appointed to pin-point the established knowledge and most urgent questions regarding: the Epidemiology, Prevention, Pathogenesis, Management, and Education in asthma. The reports from these Working Groups were extensively discussed during the final, plenary and interactive session of the World Asthma Meeting (WAM), and together these are forming the present, collaborative message from most of the international bodies that are involved in combating asthma. It is hoped that these proceedings will serve as a research agenda for the coming years, thereby contributing to a world-wide improvement of the prevention and care of this chronic disease.

\section{Epidemiology and prevention}

The objectives for the Epidemiology working group were: 1) to define what is known about the prevalence, severity and mortality of asthma in the world; 2) to define the role of Epidemiology in evaluating the risk factors for 
asthma; 3) to discuss present and proposed observational studies to describe the natural history of asthma and for the primary prevention of asthma; 4) to discuss the epidemiological studies that are needed in the fields of prevalence, cost of care and guideline development.

The objectives of the Prevention working group were: 1) to review the evidence for proposed methods to decrease the prevalence and severity of asthma, including epidemiological studies as well as trials of prevention; 2) to review primary prevention interventions, designed to decrease sensitization and/or the onset of disease and secondary or tertiary prevention interventions including allergen avoidance, designed to control the disease.

The Convenors of these two Working Groups decided that the two groups could operate most effectively if they combined. This combined meeting led to a successful and productive meeting. However, due to the time constraints that this combination imposed, the group was not able to fully address all of the objectives for both Working Groups.

\section{Multicentred studies of asthma prevalence and risk fac- tors}

During the 1990s a number of large, multicentred epidemiological studies of asthma and related conditions in children and adults were undertaken. The Working Group discussed the present status of four major surveys.

European Community Respiratory Health Survey. The European Community Respiratory Health Survey (ECRHS) [1-4] investigated randomly selected samples of $20-44$ yr olds in 35 centres in 16 countries around the world (mainly in Europe and other high-income countries). The principle hypotheses were: 1) that the prevalence of asthma, measured as symptoms and airway hyperresponsiveness (AHR), is heterogeneous within and across countries; 2) that the prevalence of atopy, measured as specific and total immunoglobulin (Ig)E, is heterogeneous within and across countries; 3 ) that there is heterogeneity in the nature of treatment for asthma. In addition a number of specific hypotheses about risk factors for asthma and atopy were tested.

International Study of Asthma and Allergies in Childhood. The International Study of Asthma and Allergies in Childhood (ISAAC) [5, 6] study measured the prevalence of symptoms of asthma and other allergic diseases in 6-7 yr old and 13-14 yr old children in up to 155 centres in 56 countries around the high and low income areas of the world. The major focus was on heterogeneity in the prevalence of disease. Hypotheses concerning risk factors have been examined by ecological analyses.

Canadian multicentre studies. These were conducted among adults in six centres using a protocol similar to the ECRHS.

Australian (New South Wales) multicentre studies. These studies in 8-11 yr old children were conducted in urban and rural parts of New South Wales (NSW). Heterogeneity in the prevalence of asthma symptoms, airway hyperresponsiveness (AHR), and atopy were examined together with specific risk factor hypotheses.

\section{What have we learnt from these studies?}

There is marked regional variation in the prevalence of asthma. This regional variation exists both within and across countries, including among high-income countries. Particular features of this inter-regional variation include: 1) higher prevalence in English-speaking countries. This was evident for measures which are independent of language: the ISAAC video questionnaire and methacholine challenge testing in the ECRHS; 2) strong West to East, and less strong North to South, gradient within Europe; 3) major differences within ethnically-similar, geographically-separate populations: between Guangzhou and Hong Kong; between Spain and Portugal and Latin America; 4) within-country variation in the prevalence of AHR may be as great as between-country differences. Substantial regional variation was observed among adults in Canada and Spain but not among children in NSW.

There is regional variation in the prevalence of atopy. The variation in the prevalence of atopy is less than the variation in the prevalence of asthma. Important findings about the variation of atopy were: 1) variation in atopy only explains part of the variation in asthma; 2) the mean total $\operatorname{IgE}$ and the prevalence of positive skin-prick tests (or specific IgE) for each centre are poorly correlated across the ECRHS. However, within each centre subjects with raised total $\operatorname{IgE}$ were more likely to have positive skin-prick tests.

Some risk factors are consistently observed across study centres. 1) Sensitization to common aeroallergens (atopy) is a strong risk factor for asthma; 2) atopy is associated with a positive family history; 3 ) increased sibship size is a protective factor for atopy; 4) certain occupational groups have an increased risk of more severe asthma.

Some observed associations require further investigation. Ecological analyses may be useful for generating hypotheses about possible risk factors requiring further exploration. The following observations about the prevalence of asthma symptoms have been made on the basis of comparisons among the ISAAC-centres. 1) the prevalence of asthma symptoms is correlated with the fat consumption as a proportion of dietary calories; 2) it is weakly correlated with per capita gross domestic product (GDP); 3) it is negatively correlated with tuberculosis notification rates but not with measles rates; 4) it is negatively correlated with the particulate pollution levels (among the Asian centres); 5) it is higher in people who use gas for cooking (in some centres in the ECRHS but not in others).

The principle limitation of these cross-sectional studies is that they give no direct evidence about the incidence of asthma or atopy. Although incidence is inferred from prevalence data, many factors simultaneously influence prevalence: treatment, disease exacerbations, disease remissions, and deaths, as well as incidence of new cases. As a consequence, it is difficult, using cross-sectional studies, to distinguish among the risk factors for each of these events or attributes. The major issue is the confusion between factors that cause people to have asthma and factors which cause people to have exacerbations of asthma. 
Comparison of levels of exposure to putative risk factors between centres with differing asthma prevalence has been useful for examining some hypotheses about the aetiology of asthma (for example, effects of air pollution and socioeconomic status). However, such ecological analyses must be treated cautiously since it is likely that many factors will vary among centres and causation cannot be attributed to any one factor. This is most obvious in the comparison between high prevalence, high-income countries and low prevalence, low-income countries where the range of differences in exposures is very substantial.

Ancillary benefits. The major international collaborative studies have had important consequences beyond their direct contribution to knowledge about asthma. Developments from these studies will greatly enhance the prospects for future international collaborations. Specific assets which have been developed are: 1) an international collaborative network of respiratory epidemiologists and teams trained to do epidemiological studies; 2) transfer of knowledge and technology necessary for the conduct of respiratory epidemiological studies; 3) standardization of methods for study of the epidemiology of asthma.

What more can be learnt from these studies? Analysis of individual risk factor data from the ECRHS is continuing. A second phase of the ISAAC is planned to examine risk factors for asthma in centres which have been shown, in the first phase, to differ in the prevalence of asthma symptoms. These additional investigations should help to elucidate individual risk factors and may explain some of the variation among countries.

A repeat cross-sectional ISAAC is planned for 2001. This will examine changes over time in the prevalence of asthma symptoms.

\section{What are the important questions?}

About risk factors. How should hypotheses be generated? The Working Group discussed two approaches to the development of a research strategy for identifying risk factors for asthma.

One approach is to test hypotheses based on current paradigms for the mechanisms of asthma. Elements of the proposed mechanistic pathway can be systematically examined and tested. This has the advantage of integration with the efforts of laboratory colleagues. However, there are several competing paradigms to choose from: e.g. the immunology and inflammation model and the abnormal smooth muscle model. Furthermore, the existing paradigms do not provide much guidance on the environmental exposures or immunological stimuli that might be the initiating factor for the cascade of events leading to asthma.

The second strategy is to follow observed associations. Hypotheses are generated by examination of unexplained variation in the prevalence of asthma. This approach does not make assumptions about the underlying mechanisms but seeks empirically to build a risk profile. An example of a suitable circumstance is the substantial difference in the prevalence of asthma between Hong Kong and Guangzhou. These are two cities which are geographically close and have ethnically similar populations. There may be important differences in lifestyle which explain the very different prevalence of asthma.
What aspects of the asthma syndrome do the risk factors influence? In considering the effect of risk factors on the expression of asthma it is important to identify the state, or aspect of asthma or allergy, which risk factors influence. Some of the relevant states, for which risk factors are sought, include: 1) atopy (any sensitization); 2) specific sensitization (for example, to house dust mites); 3) airway hyperresponsiveness; 4) asthma symptoms; 5) severe asthma; 6) exacerbations of asthma; 7) deaths from asthma.

Is the risk factor adverse or protective? It has been proposed that the expression of asthma results from the balance between a lack of protective factors for asthma and an excess of adverse factors that increase risk. To a certain extent these are simply two sides of the same coin. The absence of a protective factor represents an adverse factor.

Are there genetic polymorphisms that influence the effect of the proposed environmental risk factor? These may be an important source of interaction between genes and the environment and explain variation in the effect of some risk factors.

What types of studies should be performed to learn more about the causes of asthma? Most of the existing information on risk factors comes from cross-sectional studies. Some of the limitations of cross-sectional studies were discussed above. The Working Group agreed that cohort studies, to identify the role of potential risk factors at various stages during the evolution of asthma, are important. Several cohort studies are underway. There may be a place for a cohort study following the existing international collaborative studies (ECRHS and ISAAC). There is also a continuing role for cross-sectional comparative studies.

Existing databases such as hospitalization records, insurance and health maintenance organization (HMO) records and other routinely collected statistics provide useful information on local trends in disease prevalence but they have important limitations for aetiological research. In particular, there is a risk of selection bias due to the nonrandom entry of subjects into the study base. Furthermore, the classification of disease states may not be as rigorous as is required for research purposes leading to a risk of misclassification bias. Finally, the main limitation for risk factor research is that databases usually hold only very limited information on aetiologically-relevant exposures.

The Working Group agreed that randomized controlled trials are an important way of establishing a causal role of an environmental exposure. Of course not all exposures are suitable for evaluation in such trials. For example, it would not be possible to randomly allocate breast-feeding or exposure to environmental tobacco smoke. Randomized controlled trials of environmental modification for the prevention of asthma are expensive and lengthy. At this stage there is insufficient evidence to mount an international collaborative intervention study.

Where should researchers be looking? In high-income countries most asthma begins in childhood. In searching for exposure causing the onset of this disease it seems appropriate to look at young children. However, there 
are other population cohorts who will be informative: 1) migrants from low prevalence countries to high prevalence countries. There is some evidence that, over time, they acquire a prevalence of asthma similar to that of the destination country [7]. 2) occupational groups, to understand the development of occupational asthma; 3 ) adults with and without asthma, to understand factors leading to adult-onset disease, and to identify risk factors for a more severe course.

There is also much to learn about the aetiology of asthma by studying disease epidemics such the soybean-related epidemic in Barcelona, Spain and thunderstorm epidemics in the UK and Australia.

\section{Conclusion}

Existing data allow researchers to be confident that atopy, both in general and to specific allergens, family history, and certain occupational exposures are risk factors for asthma. The role of other environmental factors in the aetiology is not yet established.

Primary prevention trials. The purpose of randomized controlled trials for the primary prevention of asthma is to test two hypotheses : 1) that specific exposures are related to the development of asthma; 2) that specific interventions are useful in preventing asthma. Two such trials have published findings: 1) a study of food and inhalant allergen avoidance from birth to age $1 \mathrm{yr}$ in an Isle of Wight (UK) based cohort of infants at high risk of atopy by virtue of a positive family history. Compared to the control group, the intervention group experienced a reduced incidence of eczema and of allergy to house dust mite (HDM) allergen up to the age of 4 yrs [8-10]. There was no significant difference in the incidence of asthma or rhinitis; 2) a study of HDM allergen avoidance in infants with eczema or food allergy. Allergen avoidance was achieved by encasing mattresses and quilts in an impermeable cover. This Japanese study showed a reduction in the incidence of allergy to house dust mites (assessed as positive skin-prick tests) and of asthma over the ensuing 12 months [11].

\section{Ongoing studies}

The Working Group heard reports from five primary prevention intervention studies that are currently being conducted (detailed below). All these trials are directed at infants with a family history of atopy and/or asthma. The preventive interventions are implemented at, or before, birth. Four of the five trials include an allergen avoidance component. The principle outcomes are asthma and atopy.

The Working Group was aware of a sixth study, from Southampton, UK, which also focuses on the benefits of HDM avoidance for primary prevention [12]. Details of this study were not available to the Working Group.

Canadian study. This study is being undertaken in Vancouver and Winnipeg [13]. Infants with a family history of asthma and/or allergic disease were recruited and randomized into an active intervention and a "usual care" group ( $\mathrm{n}=250$, in both groups). The multi-faceted intervention was directed at avoidance of several proposed environmental and dietary risk factors for asthma: HDM, pets, "allergenic" foods (for the infants and for the lactating mother), and environmental tobacco smoke within the infant's home. Breast-feeding to age 4 months was encouraged. An intensive HDM avoidance regimen was implemented including encasing infants' and parents' mattresses, washing bedding in hot water and removal of carpets or acaricidal treatment of remaining carpets. Information on viral respiratory tract infections was collected during the study.

Outcomes at age 12 months have been assessed by a paediatric allergist. Infants were classified, principally on the basis of history of symptoms of cough and wheeze, as "no asthma", "possible asthma" or "probable asthma". The presence of rhinitis, eczema, symptoms of food allergy and positive skin-prick tests to common allergens was also elicited.

Recruitment and 1-yr follow-up have now been completed.

Manchester, UK study. This study is being conducted in infants with a strongly positive family history of atopy: both parents having positive skin-prick tests. Three hundred infants have been recruited and randomized antenatally. A vigorous HDM avoidance intervention was implemented in the active treatment group from 16 weeks gestation [14]. The intervention includes the replacement of carpets with newly fitted smooth flooring in all the infants' bedrooms; encasement of new infant mattresses' and parents' beds; hot washing all linen, provision of a vacuum cleaner with a high efficiency filter; and application of an acaricide to the lounge room floor and furnishings. Very low HDM allergen levels have been achieved in the actively treated beds.

Recruitment has been completed. The study outcomes will be the incidence of atopy and asthma.

These investigators are simultaneously conducting a cohort study to identify risk factors for atopy and asthma among infants with a negative family history of atopy. A randomized-controlled trial of early use of inhaled steroids for wheezing illness (secondary prevention) is being conducted among children with an intermediate family history (one parent atopic).

Sydney, Australia study. Six hundred infants with a family history of asthma are being recruited antenatally and randomized to one of four groups testing dietary and HDM avoidance interventions. HDM avoidance procedures in this trial include encasing the infants' mattresses and washing all bedding in an acaricidal solution at 3month intervals. Where the infant sleeps in the parents' bed, this bed is treated in a similar manner. The dietary intervention seeks to increase the ratio of omega-3 to omega- 6 fatty acids in the infants diet by giving fish oil supplements and substituting high omega-6 containing cooking oils and spreads.

Study outcomes will be the incidence of atopy, asthma and other allergic diseases. Recruitment is still in progress.

The Netherlands study. This study, which focuses on the effect of HDM allergen avoidance, is being conducted among 1,200 infants with a maternal history of atopy and/or asthma. Infants are recruited antenatally and randomized to one of three groups: mattress and pillow 
encasings to parents' and infant's bed, placebo encasings, and no encasings. Outcomes being assessed are clinical features of allergic diseases, total $\operatorname{IgE}$ and specific IgE. Recruitment has been completed and the 12-month evaluation is nearly completed. Follow-up at 4 and 8 yrs is planned.

Swedish studies. This study tests the effect of alteration in intestinal flora on the risk of atopy. Infants with a positive family history of atopy are administered lactobacillus three times a week for 6 months. The study outcomes will be symptoms of allergic disease, specific IgE and T-cell responses.

\section{Questions arising from primary prevention studies}

When should the intervention be implemented? In the current studies, the time of implementation ranges from 16 weeks gestation to the time of onset of wheezing during the first year of life. The rationale for early intervention is that it may be more effective if implemented during the period of immune system maturation and before initial sensitization to allergens.

Single, focused intervention or multi-faceted intervention. This is really a question of trial design and interpretation. Multi-faceted interventions are probably more appropriate from the public health standpoint but are more difficult to interpret as evidence for the effect of specific aetiological factors.

Will mite allergy be replaced by cat allergy (or other indoor allergens)? This would minimize or nullify the beneficial effect of intervention. It seems likely that a range of indoor allergens should be avoided.

How should outcomes be measured? The specific outcomes to be measured depend on the hypothesis being tested. However, there are important practical difficulties in measuring clinical outcomes in infants. The relevance of early wheezing illness to the expression of asthma in later life is complex. It is not yet clear which clinical, physiological or immunological markers in infancy predict the subsequent incidence of clinically important asthma.

Will early life avoidance increase the risk of later allergic response? There is a theoretical possibility that loss of antigen tolerance, which might have occurred due to early life allergen exposure, may predispose the child to sensitization when they subsequently encounter the allergen in later life. However, comparison of countries with different bedding in early childhood, for example New Zealand versus USA, does not suggest that this is a problem.

Will it be necessary to maintain avoidance for life? Interventions in infancy are based on the immunological model of immune deviation which suggests that events in early life are crucial to the life-long risk of allergic disease. This remains to be established. The occupational model and some migrant studies have suggested that acquisition of allergic disease can occur due to exposures encountered in adult life.

\section{Conclusion}

The randomized-controlled trials that are currently underway have not yet progressed to a stage that permits definite conclusions to be drawn about the effectiveness of interventions for primary prevention of asthma.

Interventions for people with asthma (tertiary prevention). The role of preventive measures in people with established asthma was not reviewed comprehensively by the Working Group. Deliberations on the role of allergen avoidance and disease management are summarized below. There are several other exposures (which were not discussed) which may contribute to adverse outcomes of asthma for example, environmental tobacco smoke, air pollutants, and diet.

Allergen avoidance. The first objective evidence that avoidance of household allergens could be effective in the management of asthma came from the studies of Storm van Leeuwen in The Netherlands in 1929. Storm van Leeuwen showed that approximately $75 \%$ of asthmatics who moved to a "climate chamber" improved. Since that time many studies have investigated different aspects of allergen avoidance as treatment for asthma. The studies can be divided into three categories: 1) avoidance in a sanatorium or hospital room [15-18]; 2) controlled trials of avoidance measures in a patient's house [19-23]; 3) detailed studies of methods used to control exposure to dust mite, cat, or cockroach allergens [16, 24-26].

The sanatorium or hospital room studies have been almost uniformly successful, demonstrating decreased symptoms, decreased medication requirements and progressive decreases in AHR over weeks or months [15-18]. However, the benefits seen in these studies could be attributed to any one or more of reduced exposure to mite, animal dander and fungal allergens, as well as removal from family, change in diet and regular exercise.

The published controlled trials of allergen avoidance in the treatment of asthma all relate to dust mite allergic individuals and the results have been mixed. The problems with these studies have been of several kinds: many of the studies have been too short in duration and over half did not achieve a decrease in allergen exposure. There are five published controlled trials that have achieved a prolonged decrease in allergen exposure [19-23] and four of these $[19,21-23]$ have reported a significant improvement in symptoms and AHR in the active treatment group. It is this evidence that led the National Allergen Exposure Prevention Programme (NAEPP) to recommend specific advice about allergen avoidance as a first line treatment for all patients with persistent asthma.

Reducing exposure to major indoor allergens requires an understanding of the biology of the source, and the factors that influence the distribution within the house. This has become possible because indoor allergens have been purified and sensitive assays developed. The distribution of mite allergen within a house is very different from that of cat or dog allergen. Mite allergen is carried on large particles, only becomes airborne during disturbance and is not distributed into other houses or schools. By contrast, cat allergen is carried on smaller particles that can remain airborne and can be reduced with an air filter once the source is controlled. Animal dander allergens are spread 
widely through the community so that exposure can occur away from the source. In summary: 1) mite avoidance can be achieved but requires vigorous measures to control or isolate the sites of growth; 2) reducing exposure to cat allergens if the cat remains in the house requires aggressive measures including treating the cat, reducing reservoirs and air filtration. These measures are difficult to maintain experimentally and have not been achieved in a controlled trial; 3) reducing exposure to cockroach allergens requires cleaning to reduce the reservoirs, aggressive control of food sources and extensive baiting of the house. This approach as a method of treating asthma has not been achieved on a consistent basis.

Disease management. The Working Group discussed the issue of health services research. There is a need for this research to encompass the needs of low-income countries. New strategies are required to improve access to effective health care for all people with asthma regardless of their financial status or ability to pay.

\section{Future research directions}

The aim of research into risk factors, treatment and prevention of asthma is to make recommendations for public health action to ameliorate the burden of asthma in the community. The process includes the following steps: 1) identifying candidate risk factors for asthma from: a) targeted cross-sectional studies comparing heterogeneous populations; b) cohort studies in various risk groups; and c) nested case-control studies within existing cohorts; 2) proposing interventions designed to modify risk factors in subjects at risk of the development of asthma; 3) implementing randomized controlled trials to test the effectiveness of these interventions; 4) evaluating their cost-effectiveness; 5) making recommendations based on these evaluations. Specific recommendations should be targeted at: a) public policy makers, such as politicians and health bureaucrats; b) health care providers, including primary care providers and hospitals; c) health care consumers, that is, patients; d) general community; e) research community and research funders.

Currently progress towards interventions for the prevention of asthma is being made along the first three steps.

\section{Pathogenesis}

The working group on asthma pathogenesis chose to focus on six areas that they felt were important and in which progress was likely to be possible in the near future. This selection does not mean that other areas not mentioned are unimportant, but with the constraints of the WAM, some selectivity was required. The six topics selected were: 1) the early life origins of atopy and asthma; 2) what translates atopy into asthma?; 3) intrinsic and nonIgE mediated asthma; 4) T-cell regulation of asthma; 5) the role of the epithelium as victim or perpetrator in asthma; 6) the relevance of airways remodelling.

\section{Early life origins of atopy and asthma}

Established facts. 1) atopy, the ability to make specific IgE to environmental allergens, is so common that it should not be regarded as a defect; 2) the individual propensity for atopy and asthma is genetically determin- ed, but the large regional variations in atopy and asthma are due to environmental factors $[1,6]$; 3) the fact that maternal atopy and asthma have a major influence on the early development of atopy and asthma in offspring suggest a priming effect of the mother on the foetus. The mother contributes genetic risk factors but the uterus serves as an environment in which the foetal immune system develops and in which other aspects of maternal health and nutrition have an impact [27]; 4) allergic disease is to a considerable extent the consequence of a deficient downregulation of immune responses to allergens [28]; 5) in foetal life there is a normal and universal skewing of T-lymphocyte responses towards the T-helper cell (Th) 2 cytokine profile [29]. This both down-regulates maternal Th1 responses, thereby preventing foetal rejection, and probably encourages normal foetal growth. The postnatal maturation of T-cell responses to aeroallergens in atopic and nonatopic infants suggests that the continuation of fetal allergen-specific $\mathrm{Th} 2$ responses is a feature of the inductive phase of atopy [30]. It may help to sensitize the foetus to its mother's intestinal parasites thereby providing efficient early protection against parasite exposure during delivery. The mechanism by which this occurs has yet to be established, but recent data suggest that amniotic fluid contains cytokines, immunoglobulin and antigen which would facilitate foetal exposure via the skin, respiratory tract and gut to those antigens in the maternal environment. The foetal gut contains remarkably mature antigen presenting cells, B-cells and T-cells from as early as 16 weeks gestation [31, 32]; 6 ) if Th2 skewed immune responses are a normal phenomenon in foetal life, then the key event must be the switch of response towards the Th1 pattern either in late pregnancy or in the early postnatal period. Most recent attention has focused on some infectious diseases, which may prevent the development of atopy [33] and the microbial environment as being important in this T-cell phenotype switching [34]. While infection may, in some circumstances, switch the response, it is also possible that normal commensal gut flora triggers a "bystander stimulation of Th1-associated immune responses" [35]; 7) early onset atopy is the strongest predictor for subsequent asthma and also for the persistence of asthma through adolescence into adult life. Studies have identified that this occurs particularly in relation to sensitivity to egg, HDM, grass pollen, the mould Alternaria, and cat allergen. This is entirely dependent on environmental exposures in early life, and therefore varies from one environment to another. It is therefore an antigen nonspecific phenomenon. Whether the early onset of atopy is the cause of asthma and its persistence, or merely an associated phenomenon, has not yet been established [36, 37]; 8) genetic polymorphisms may determine subtypes of asthma, including the timing and pattern of disease onset, disease progression and severity. Some gene defects may be local, and others may be time-limited. There is a need for greater understanding about gene defects which may overlap with other inflammatory diseases and how genetic polymorphisms may influence responsiveness to pharmacological agents [38-40].

Research agenda. 1) understanding the regulation of primary immune responses to allergens; 2) examining the impact of microbial flora on immune regulation; 3) which lifestyle factors are triggering allergy and immune deviation?; 4) unravelling the genetics of atopy and asthma, especially polymorphisms (see above). 


\section{What translates atopy into asthma?}

Established facts. 1) The majority of patients with asthma which develops in the first three decades of life have evidence of atopy or allergy. They have elevated IgE concentrations, positive skin tests and clinical symptoms in association with allergen exposure. Inhalation of allergen can cause an early as well as a late phase bronchoconstriction in patients with asthma, and also in patients with allergic rhinitis. The allergic rhinitis patient, however, does not have spontaneous episodes of wheezing. The question of what converts atopy into asthma is important and holds valuable insight into mechanisms of asthma. 2) there is evidence that the amount of antigen exposure, in early life, influences the age at which wheezing begins [41]. The nature of the allergen, its particle size, any enzymatic properties and the allergen load are also relevant; 3 ) certain viral respiratory infections, particularly early in life, will not only enhance the allergic diathesis but also increase the likelihood that asthma will be associated with atopy [42-44]. However, epidemiological data suggest that having older siblings is protective against atopy [45], and this is presumed to be due to an effect of respiratory infections deviating the immune response from a Th2 towards a Th1 pattern; 4) some patients with allergic rhinitis experience wheezing when their hay fever symptoms intensify. It is not clear whether this means that asthma has always been present and became symptomatic only with the development of active rhinitis symptoms, or alternatively that the upper airways influence lower airway function [41, 42]; 5) airways eosinophilia is a characteristic feature of asthma and is associated with the severity of the disease [46]. The cytokine pattern associated with this response includes interleukin (IL)-5, regulated on activation, nor-mal T-cell expressed and secreted (RANTES), eotaxin and IL-4 [47, 48].

Research agenda. 1) What are the implications of early respiratory infection for aetiology, prevention and therapy?; 2) what role do counter-regulatory cytokines such as interferon (IFN) $\gamma$ or IL-10 play?; 3) are researchers dealing with a single airway from the nose to the alveoli or is there focused inflammation, driven either by organspecific gene activation or T-cell trafficking to certain parts of the respiratory tract?; 4) does the eosinophilicenhancing immune response lead to airway inflammation and hence to asthma?

\section{Intrinsic and non-IgE mediated occupational asthma}

Established facts. 1) A general consensus has been reached for a definition of nonatopic (intrinsic) asthma, i.e. patients with asthma who are not allergic to common allergens, and have no history of atopic diseases. However, there are problems with a negative definition and conversely, it is difficult to accept that asthma in a patient with a positive skin test to HDM always means that mite allergy is responsible for the asthma. Aspirin sensitivity and non-IgE-mediated occupational asthma also present difficulties of classification; 2) some peculiarities may be recognized in the clinical presentation. Thus nonatopic asthma is more frequent in females and usually starts later in life than atopic asthma; the onset is often preceded by a respiratory flu-like illness; nasal polyps and aspirin sensitivity are particularly frequent; nonatopic asthma often has a more severe clinical course than atopic asthma; 3) the histological characteristics of nonatopic and atopic asthma are broadly similar, with elevated numbers of activated eosinophils and T-lymphocytes in the bronchial mucosa and elevated expression of pro-eosinophilic cytokines (IL-5, IL-3, IL-13, granulocyte-macrophage colony-stimulating factor (GMCSF) and CC chemokines which interact with CCR3) [45-50]. The only cell type which shows any distinction between intrinsic and atopic asthma is the macrophage, with increased expression of CD68 in intrinsic asthma; 4) occupational asthma is an interesting model of asthma since exposure to the occupational agent may be characterized and controlled. Several studies have led to a better understanding of the mechanisms of occupational asthma [51-54]. Moreover, cessation of exposure may lead to a remission of the disease $[55,56]$ or its persistence. Understanding the reasons for these trends may be of importance for the long-term prognosis of nonoccupational asthma.

Research agenda. 1) Is there a role for IL-4 in nonatopic asthma?; 2) does local IgE production occur in the bronchial mucosa of nonatopic asthmatics?; 3 ) is nonatopic asthma virally induced?; 4) is nonatopic asthma an autoimmune disorder?; 5) is there a role for occupational antigens in nonatopic asthma?; 6) is nonatopic asthma a single entity or do different mechanisms lead to the same clinical expression?; 7) are there differences in response to drugs between atopic and nonatopic asthma?; 8 ) is there local $\mathrm{IgE}$ production in nonatopic asthma? Is it relevant to the disease?; 9) what is the significance of CD68+ macrophages detected in nonatopic asthma bronchial submucosa?

\section{T-cell regulation of asthma}

Established facts. 1) The pathology of asthma is associated with disturbances in an extremely complex cytokine network [57]. 2) asthma seems to be a T-cell-driven disease, but many cell types, including eosinophils, mast cells, basophils, B-cells and macrophages are involved, and several of these can release Th2-type cytokines including IL-4, IL-5 and GM-CSF; 3) patients with severe asthma have increased levels of activated CD4+, CD25+ T-cells in their peripheral blood and bronchi [58]; 4) cytokine production profiles of T-cells, isolated from bronchoalveolar lavage (BAL) or bronchi, or detected directly by immunohistochemistry in bronchial biopsies are characterized by the production of $\mathrm{Th} 2$ cytokines $[47,59]$. This Th2 cytokine production profile is expressed by CD4+ as well as CD8+ cells [60]. Nevertheless, the polarization of T-cells into Th1 and Th2 subtypes appears to be more true in mouse than in man [61] and the paradigm of asthma as a Th2 disease cannot be completely demonstrated [62].

Research agenda. 1) Given that cytokines are the major driving force of T-cell differentiation [58, 63], which other cell types are involved in the induction of (allergenspecific) Th2 cells in asthma?; 2) what are the relative 
frequencies of allergen-specific versus nonspecific T-cells in the bronchial mucosa?; 3) do specific subsets of T-cells home into the bronchial mucosa of asthmatic patients, as has been shown for accumulation of T-cells in the skin of patients with atopic dermatitis [64], and if so, which are the homing receptors involved in this process [65]?; 4) what is the role of chemokines and their receptors in the infiltration of T-cells in the bronchi of asthmatic patients [66-68]?; 5) what is the role of CD8+ T-cells in the pathogenesis of asthma [69]?; 6) is it possible to restore the Th1/Th2 balance by influencing the cytokine milieu, rather than by targeting the T-cells themselves?

\section{Role of epithelium in asthma}

Established facts. 1) Epithelium is an important physical barrier, between the target tissues and various antigens and noxious stimuli, as well as between inflammatory mediators and target tissues, and between therapeutic agents and the target tissues; 2) the epithelium responds to injury: the epithelium in asthma is more fragile and often observed to be sloughed along a particular cleavage plane. This, and its relevance to the pathogenesis, is much debated; 3) dendritic cells [70] and other "epithelial" cells act as antigen presenting cells and initiate allergic inflammation by their interaction with resident intra-epithelial lymphocytes. Dendritic cell and lymphocyte traffic occurs. The timing, during infancy, of their exposure to infection/allergen is critical to the later development of the allergic condition and asthma; 4) the epithelium is a rich source of mediators/cytokines that have a variety of important biological functions in the lung, including inducing bronchoconstriction, promoting inflammation and promoting remodelling [71]. These include: a) lipid mediators: prostaglandins, thromboxanes, leukotrienes, platelet activating factor (PAF), hydroxyeicosatetraenoic acid (HETE) [72]; b) pro-inflammatory cytokines: tumour necrosis factor (TNF) $\alpha$, IL-1, IL-2, IL-6, IL-10, IL-11 [73]; c) chemokines: IL-8, RANTES, eotaxin, monocyte chemotactic peptide (MCP)-1, MCP4, growth-related oncogene protein (GRO $\alpha$, GRB $\beta$ ), IL-16 [74]; d) colony-stimulating factors: GM-CSF, granulocyte colony-stimulating factor (G-CSF) [75]; e) growth factors: transforming growth factor (TGF)- $\beta$ [76]; f) nitric oxide [77]; g) epithelial derived relaxant factor, epithelial derived constrictor factor; h) peptides: e.g. endothelin $[78,79]$; i) peptidases [80]; and j) adhesion molecules $[81,82] ; 5)$ the resultant profile and balance of these molecules determines the nature, severity and longterm consequences and extent of airway wall remodelling including thickening of the reticular basement membrane and enlargement of bronchial smooth muscle mass; 6) the epithelium not only recruits inflammatory cells from the vascular compartment, providing a chemical gradient of chemoattraction, but also regulates the clearance of inflammatory cells by retention or induction of apoptosis of inflammatory cells; 7) movement across the epithelium of transudate and exudate (i.e. protein and inflammatory cells) leads to airway plugging by a highly tenacious secretion [83]. The epithelium modulates secretory events in asthma, producing both mucus and secretagogues.

Research agenda. 1) How do epithelium, pollutants, and viruses interact in the development of allergic inflammation? 2) is epithelial "injury" a common feature of sev- eral inflammatory conditions (including asthma, chronic obstructive pulmonary disease (COPD), bronchiectasis and fibrosing alveolitis) but with differing resultant patterns of pro-inflammatory molecules? If so, why?; 3 ) is the epithelium abnormal to start with and therefore prone to injury, or does it become abnormal as the result of injury? If so, is the response to injury normal or abnormal?; 4) what are the factors that control epithelial cell apoptosis and replication? What is the appropriate model in which to study these phenomena?; 5) what role does the epithelium play in controlling transudation and mucus formation?; 6) what is the role of the epithelium in regulating airways remodelling? Is this mediated through cytokines, growth factors or neurogenic inflammation?; 7) can key epithelial pro-inflammatory molecules or their receptors be blocked to reduce the inflammatory response? Which molecules should be targeted?

\section{Airways remodelling: important or epiphenomenon?}

Established facts. 1) The asthma paradox: according to standard definitions, symptoms of asthma are usually associated with variable airflow limitation that is reversible either spontaneously or with treatment. However, it is known that asthma is a chronic inflammatory disorder of the airways and the airways inflammation produces changes in the airwayswall (remodelling) which seem largely irreversible with standard therapy [84]. So, how reversible is reversible asthma?; 2) in children and adults with asthma, the lamina fibro-reticularis is thickened $[85,86]$ as the result of an abnormal deposition of extracellular interstitial matrix components such as fibronectin, collagen type I, III and V [85], tenascin [86] and laminin $\beta 2$ [87]. The degree of subepithelial layer thickness is weakly but significantly correlated with baseline forced expiratory volume in one second (FEV1) [88], the degree of methacholine hyperresponsiveness $[88,89]$ and clinical disease severity scores [90]. In addition, subepithelial collagen deposition tends to increase in more severe asthma [91, 92]. Indirect evidence of airway remodelling may be found using computed tomography (CT)-scans [93]. These changes may contribute to persistent abnormalities in lung function in some patients with asthma, but not by any means in all patients; 3) some of these changes are "irreversible" while others can be reduced by "anti-inflammatory" therapies; 4) subjects at risk of developing chronic asthma show a mild degree of subepithelial collagen deposition. Patients with seasonal asthma [86] and with allergic rhinitis [91, 94] show an irregularly distributed subepithelial fibrosis. The degree of subepithelial collagen deposition in asthmatics is significantly related to the number of fibroblasts in the submucosa [95] and the expression of TGF- $\beta$ in epithelial and submucosal cells [76]. The reduction in the thickening of the subepithelial reticular layer seen in some studies after corticosteroid treatment could be due to a decrease in the number of fibroblasts and of activated eosinophils or to an increase in matrix metalloproteases [96]. A reduction in the deposition of collagen type III and tenascin [86] has been reported after therapy with inhaled steroids. Although elastic fibres are disrupted in asthma [97] and elastase levels are increased in sputum from asthmatics [98], short-term or long-term treatment with corticosteroids does not reduce the content of elastic 
fibres [99]. In addition, after a prolonged period of stimulus avoidance, a small but significant reduction in the degree of subepithelial thickening has been noted in isocyanate-sensitive asthmatics [100]; 5) the airway wall of patients with asthma is also characterized by an increase in muscle mass $[101,102]$ in mucous glands [102] and in vessel area leading to a thickened airway wall and a markedly and permanently reduced airways calibre. These features result in an increased resistance to airflow particularly when there is bronchial contraction and AHR [103]. The effect on airflow is compounded by the presence of increased mucous secretion and inflammatory exudate, which not only blocks the airway passages but causes an increased surface tension favouring airway closure; 6) airway remodelling in asthma seems to be due to a combination of the increased release of profibrotic growth factors and an imbalance between synthesis and degradation of the extracellular matrix; 7) eosinophils are important inflammatory effector cells in bronchial asthma. Release of eosinophil basic proteins is associated with tissue destruction and, as a consequence, airway remodelling in asthma. Eosinophils may also actively participate in the remodelling process by synthesizing and releasing factors, that can directly stimulate fibroblasts such as TGF- $\beta$ [104]. TGF- $\beta$, and epidermal growth factor (EGF) have been reported to be highly expressed in asthmatic airways [76, 105]. Eosinophils also play a critical role in the degradation of the interstitial matrix, a process which is important for the reorganization of the airway architecture. Together these data suggest that eosinophils play a major role in the irreversible process of airway remodelling. Since inhibition of eosinophil apoptosis is one important mechanism leading to their accumulation in allergic tissues [106, 107], the induction of eosinophil apoptosis appears to be a reasonable approach for both reduction of inflammation and prevention of airway remodelling in asthma.

Research Agenda. 1) Researchers need a standardized consensus definition of airways remodelling that incorporates information from histology, morphometry, and immunohistochemistry using samples from intrinsic versus extrinsic asthmatics as well as appropriate controls (including those with other lung diseases); 2) to what extent is this remodelling process a normal response to an abnormal injury or is the response itself abnormal?; 3) what perpetuates the remodelling process?; 4) does the heterogeneity in time and extent reflect genetic variation or environmental factors?; 5) how early does remodelling begin?; 6) how does remodelling progress?; 7) is remodelling reversible?; 8) can the remodelling process be altered and do any of the current anti-inflammatory strategies make any difference to the long-term outcome?; 9) can a useful and relevant marker (or markers) of remodelling be found?; 10) does airways remodelling change the behaviour of airways smooth muscle, thereby promoting a force-maintaining "latch"-state of the muscle in asthma [108]?

\section{Management}

The workgroup discussion centred on the global approach to the management of asthma and the usefulness of therapeutic guidelines for the different health care settings in the world. The starting point for the discussion was the revised version of the Guidelines for the management and prevention of asthma, released by GINA at the occasion of the World Asthma Day [109].

\section{Classification of asthma by severity}

Established issues. The classification of both chronic and acute asthma by severity is based on consensus, both in adults and children. There are only minor differences between the different asthma guidelines and they are irrelevant [109-115]. The GINA guidelines distinguish four steps of severity in chronic asthma: intermittent, mild persistent, moderate persistent and severe persistent. The steps differ with regard to the frequency and the severity of the symptoms, the interference of the symptoms with daytime activities and sleep, the degree of airflow limitation and the baseline therapy. The classification by severity of chronic asthma is useful for the education of health care workers so that they can learn how to manage asthma and when to refer a patient to a more sophisticated level of health care. This allows an appropriate assignment of health care resources. The classification by severity should be adapted nationally and locally, dependent on the availability of diagnostic tools such as peak flow meters. The level of education of the health care workers must also be taken into account.

Remaining questions. 1) Although the consensus criteria for classification are helpful, their impact would certainly be strengthened if clinical and epidemiological studies would provide evidence that the criteria are relevant to important outcome measures. These could include requirements for different forms of treatment to obtain control of asthma, risk of severe exacerbations, morbidity and mortality, quality of life and use of health care resources; 2) better criteria are needed for referral of patients with asthma within health care systems. The criteria will of course depend on the organization of the health care system, the education of the health care providers and the available resources; 3 ) in classifying the severity of chronic asthma in children, roughly the same characteristics are used as in the classification of adult asthma. It is very probable that the manifestations of uncontrolled asthma are different in children, especially the younger ones. The level of daily activity and the absence from school might be useful criteria to characterize the impact of asthma on individual asthmatic children. The specificity and sensitivity of these criteria need to be investigated. They indeed present characteristics that can be influenced both by the asthmatic disease and by familial, psychological, social and economical factors; 4) international studies on the prevalence of asthma have been very useful in mapping asthma as an important global health issue. Prevalence of a disease is certainly not the only determinant of its health care impact. Of greater importantance might be the distribution of the different categories of severity of chronic asthma and the frequency and severity of acute asthma exacerbations. International studies on the distribution of these categories should be performed and should allow the identification of differences between countries and regions, when similar criteria are used; 5) in children aged 
$<5 \mathrm{yrs}$, it is often very difficult to differentiate wheezing caused by a viral respiratory infection from an exacerbation of asthma. Studies should be done to identify clinical criteria for a viral respiratory infection in children of that age. The establishment of validated clinical criteria might be helpful for the diagnosis and appropriate treatment of episodes of wheezing in children $<5$ yrs old; 6) although the symptoms of asthma in patients with intermittent asthma are usually mild and brief, occasionally some patients might have intermittent severe asthma. No controlled studies have identified the appropriate management of this type of patient. They are rare and usually the management consists of the treatment of their acute severe exacerbation. Further research is needed into the identification of the optimal chronic management and/or the early detection of worsening asthma of this type of patient; 7) there is also a general problem in defining and characterizing worsening of asthma. The spectrum of worsening of asthma varies from brief symptoms with a duration of a few minutes to a few hours, which responds very well to treatment with a short acting inhaled $\beta$-agonist, to the life-threatening severe exacerbation. The characteristics of an episode of worsening of asthma that leads into a severe exacerbation are not very well known. The possibility of differentiating such an exacerbation from a milder worsening of symptoms, should allow an optimal show of therapy and monitoring.

\section{Management of chronic asthma}

Established issues. All asthma guidelines [109-115] agree on the objectives of the management of chronic asthma, namely control of asthma. This is defined by the absence of symptoms and exacerbations, no need for rescue medication or emergency room treatment, normal activities including the possibility to perform exercise and sports, normal lung function and absence of side effects from the treatments. The choice of medication and health care resources is dependent on the severity of the chronic asthma. Inhaled glucocorticosteroids are the basis of the treatment of chronic asthma for all types of severity, except intermittent asthma. The inhaled glucocorticosteroids can be used in different doses and combined with other controller medication. Short-acting $\beta_{2}$-agonists are the best rescue medication. Immunotherapy is considered to be insufficiently effective, poorly standardized and too costly to be recommended for developing countries. Although traditional methods of healing are frequently and increasingly used, their efficacy has not been established and their use cannot be recommended.

Remaining questions. 1) There is a huge need for an international action, maybe by the WHO and the World Bank, for making effective asthma therapy available in all countries all over the world. More specifically inhaled glucocorticosteroids should be available in all countries. They have proven to be cost-effective in different health care systems and in both developed and developing countries. 2) more research should be done on the identification of the cost-effectiveness of various combinations in the treatment of patients with moderate and severe persistent asthma. More specifically cost/efficacy of the combination of inhaled corticosteroids with long acting inhaled $\beta$-agonists, slow released theophylline and antileukotrienes should be studied. The place of the new antileukotrienes in the management of chronic asthma is not fully established. Comparative studies with existing and well-established therapy should be done in all types of chronic asthma. Control of asthma should be the primary variable. 3) in view of the widespread use of immunotherapy and traditional methods of healing in the management of chronic asthma, further research is needed to compare the efficacy and the cost efficiency of these forms of treatment with the classical pharmacotherapy. 4) avoidance measures for allergens and other asthma triggers have been shown to be effective. Most of them are too expensive or impractical for implementation in families with a low income. Cheaper methods for allergen avoidance should be investigated.

\section{Management of acute asthma}

Established issues. 1) The role of short-acting inhaled $\beta_{2}$-agonists and oral glucocorticosteroids in the management of acute worsening of asthma has been sufficiently proven [109-115]. There is also good evidence that intravenous aminophyllin is a valuable alternative to short acting inhaled $\beta_{2}$-agonists, if these agents are not available; 2 ) the classification of severity of acute worsening of asthma is based on clinical criteria but the availability of a peak flow meter during the assessment of an acute asthma attack is helpful. The criteria for hospitalization of a patient with an acute severe asthma exacerbation are well established. There is general agreement on the criteria for starting oral glucocorticosteroids in the treatment of acute severe asthma and the need to identify patients at a high risk of mortality.

Remaining questions. 1) Although many studies have shown that short-acting inhaled $\beta_{2}$-agonists can be given either via a large volume spacer or via a nebulizer, these devices are often not available in developing countries. There is currently an ongoing trial looking at the efficacy of a cheap spacer made with a plastic bottle; 2) further efforts should also be made to train nurses and other health care workers for the treatment of acute asthma. A strategy for adequate follow-up and optimal maintenance treatments after an acute exacerbation in different health care settings needs further development.

\section{General recommendations}

1) Although most of the aspects of the management of asthma are based on a generally accepted consensus [109115], more studies are needed to provide strong evidence to support the current management strategy. The existing consensus should only being changed when sufficient evidence is available to do so; 2) a major effort should be made to educate health care workers at all levels on the diagnosis and management of asthma; 3 ) the cost-effectiveness of nonpharmacological treatment of asthma should be compared with that of pharmacological treatment; 4) an international effort should be made to make effective antiasthma treatment available to all asthmatic patients, independent of their socioeconomic status. 


\section{Education}

Delivering effective care to those with asthma requires a partnership between patients and health professionals, both of whom are educated and organized in an effective manner in an adequately funded system. There needs to be good communication between patient and health professional, where prescriptions and devices are offered in a manner which makes it likely that they are used, and within an environment which recognises that there are many stakeholders involved in quality asthma care.

These WAM proceedings can only summarize the key points regarding current knowledge in this area and to highlight the key research questions remaining. A more comprehensive state of the art review will follow in a subsequent publication.

\section{Communication}

A recent review of 21 studies conducted over a 10-yr period revealed that the quality of communication influenced patient health outcomes and is associated with reduced malpractice claims [116]. Two recent randomized controlled clinical trials demonstrated the vital role of good communication within consultations/healthcare visits if patients are to be satisfied with their medical care and manage their condition satisfactorily $[117,118]$. Several studies have shown how health professional communication skills can be improved [118-120], with key components of positive health professional communication being: 1) a congenial demeanour (friendliness, humour, showing attentiveness); 2) engaging in interactive dialogue; 3) giving encouragement and praise empathy and reassurance (eliciting and acknowledging patients fears and immediately dealing with any concerns); 4) giving patients information about what to expect in the visit and information about the condition and treatment $[118$, $121,122]$; 5) eliciting shared goals and individualizing information about both medication and lifestyle; 6) giving feedback to the patient about how they are doing and performing regular reviews. These approaches need to be tailored for asthma severity/frequency and different age and cultural groups.

Verbal communication should be reinforced by different techniques, such as videos, audiotapes, and leaflets, together with specific teaching programmes developed for specific client groups [123]. The most preferred and successful education materials are those which are personalized and interactive [124]. Although patients want written information they are not always provided with what they want, and such materials are not always appropriately written [125]. There is no clear evidence that audiovisual material is preferable to simple written material, alone or in a supplementary role.

\section{Patient education and self-management}

There is reasonable consensus on the knowledge and self-management skills that patients should possess as a result of education [126]. They should: 1) accept that asthma is a long-term and a treatable disease; 2) be able to accurately describe asthma and its treatment; 3) actively participate in the control and management of their asthma; 4) identify factors that make their asthma worse; 5) describe strategies for avoidance or reduction of exacerbating factors; 6) recognise the signs and symptoms of worsening asthma; 7) follow a prescribed written treatment plan; 8) use the correct technique for administering medications including inhalant medications via metered dose inhaler (MDI)s, dry power inhaler (DPI)s, diskhalers, spacers or nebulizers; 9) take appropriate action to prevent and treat symptoms in different situations; 10) utilize medical resources appropriately for routine and acute care; 11) monitor symptoms and objective measures of asthma control; 12) identify barriers to compliance (adherence) to the treatment plan; 13) address specific problems that have an impact on their individual condition.

Such patient education on aspects of self-management and self-treatment can achieve benefits in terms of increasing knowledge, reducing morbidity, enhancing compliance and in reducing use of health service resources [127-144]. Information alone is insufficient and successful interventions combine the giving of information with individualized self-treatment (action) plans and instructions and strategies to motivate patients to engage in self-monitoring and regular medical reviews. Such "action" plans may be based on symptoms, peak flow or both.

A recent systematic review by the Cochrane Airways Group [145] showed that teaching self-management skills work. The most successful studies have been those which include self-treatment (action) plans. Twenty-two studies comparing self-management with usual care were reviewed and showed that self-management reduced hospitalization (odds ratio (OR) 0.57), emergency room visits (0.72), unscheduled visits to the doctor (0.57), days off work or school (0.53), use of $\beta_{2}$-agonists and symptoms.

Two approaches to integrating educational activities into clinical care have been studied. The first is for clinicians to provide the essentials of asthma education during clinical contacts with patients. Two studies have shown that training physicians to use communication and patient education skills results in increased teaching being reported by patients $[118,146]$. Four studies have shown that teaching by physicians or nurses is associated with improved patient outcomes [134, 138, 147, 148]. The teaching of such self-management skills may successfully occur in a variety of hospital settings, including emergency rooms $[143,147,149]$, and with less certainty of success in general practice or primary care. In addition, specific instruction in self-treatment (action) plans has been successfully demonstrated in hospital out-patients [150-152]. The second approach is to refer patients to organized asthma education programmes sponsored by or associated with the clinical setting. Such programmes have been effective in promoting prevention and treatment strategies by reaching community members not receiving appropriate care or education through the conventional health care system. For example, community based education programmes often targeting harder to reach groups have been shown to be effective [153-155]. Community organizations have also been used to deliver appropriate education and - although difficult to evaluate - have been found to be effective $[134,153]$.

Schools offer a unique setting for asthma education and provide an opportunity to reach large numbers of children 
independent of their access to medical care. Studies have been predominantly conducted in the USA $[156,157]$ where benefits were observed in health behaviour, reduction of asthma symptoms and school performance. A new approach to asthma education in adolescence is appearing where the educators are the young people themselves and it is delivered in the school environment to maximize coverage [158].

Although research-evaluating education for asthma has been conducted in many settings as outlined above, there have been no studies explicitly comparing the value of specific settings for education. Thus to date no clear evidence is available that one setting is best: rather each offers specific advantages and limitations that can be viewed as shaping the educational goals that can be attained. It would seem reasonable to expect that education should be available at every interface in whichever setting.

Careful study of the cost effectiveness of self-management programmes has shown positive results [123, 128, 142, 159-162]. The cost benefit ratios being between 1:2.5 and $1: 11.22$, meaning that the programme with the most favourable result brings a saving of $\$ 11.22$ for every dollar spent. In many of the published studies, however, a common effectiveness variable, such as symptom-free and/or episode-free days are lacking. Furthermore, since most published studies only cover the initial year of treatment/ intervention, the cost effectiveness of self-management programmes in asthma is likely to be under-estimated in the reported studies.

Lay and health professional liaison in asthma and the role of patient support organizations and asthma telephone helplines

The growing number of initiatives between lay people and health professionals suggest that existing health care services may be unable to meet the needs of the asthma population at large and that traditional education programmes and dissemination of practice guidelines may not be reaching and changing the behaviour of practising healthcare professionals. A variety of lay and health care liaison projects at community and regional levels are underway $[153,163,164]$. In addition, 21 of the 44 Asthma Associations mentioned in the GINA Directory of Asthma Associations [165] run a telephone helpline. The effectiveness of such helplines and that of patient support organizations remains to be formally evaluated.

Implementation of guidelines, health professional education and models for national training

Implementation of guidelines and practice based education. 1) Adherence to national guidelines is uneven [166] and may have worsened with time in areas of lower socioeconomic levels [167, 168]. Despite the widespread development of large numbers of asthma guidelines, there are few high quality trials testing their implementation in practice. However, conclusions from the few trials that exist, broadly support the findings of five systematic reviews addressing education interventions in other clinical areas [169-173]; 2) guidelines can change practice and improve patient outcomes [169].
Change is more likely when guidelines are disseminated to healthcare professionals using a specific educational intervention (such as a practice-based discussion meeting), and implemented using patient-specific reminders to prompt the healthcare professionals about recommendations during consultations (table 1); 3) multiple implementation strategies are probably more effective [170]; 4) national guidelines distributed without implementation strategies are unlikely to be effective. Local adaptation and implementation is a practical and effective strategy [169]. There is a need to test and evaluate approaches to dissemination into various settings (for example primary care physician, community and other professionals). 5) studies do not point to any one universally effective guidelines implementation strategy, only ones which are more or less effective in particular settings; 6) guidelines are only one of a number of tools, which can change clinician behaviour [173]. Others include institutional policies incorporating incentives and sanctions and various types of decision support strategies; 7) educational outreach visits are an important and effective way of changing clinician behaviour, especially prescribing. Their effect is enhanced when combined with strategies targeting barriers to change (e.g. administrative, attitudinal), and with other behaviour change strategies (e.g. reminder systems) $[173]$; 8) educators who are not peers can also be effective; 9) remote strategies (e.g. telephone detailing) and nonpersonal strategies (e.g. electronic guidelines summaries) are weakly effective.

Qualitative studies highlight administrative, organisational and workload related barriers to behaviour change.

Models for national training. Evidence based training is essential to prepare health professionals for greater involvement in asthma management. There is little evidence to show that national training centres are worthwhile, but general practices running asthma clinics by a specialist asthma nurse trained at a national training centre had more patients operating self-management plans, fewer patients with symptoms and days lost from work due to asthma, fewer acute attacks, and were more aggressive in giving patients short courses of systemic steroids than other practices [174].

Training is available on a national basis, for example in New Zealand, Canada and the UK. In the UK specialist training has been shown to be associated with favourable patterns of structure, process and clinical outcome [175, 176] and has demonstrated that those with diplomas from such training programmes are more likely to discuss the patients' worries and anxieties than other health professionals [177].

Those who teach patients and offer their carers and families asthma information and self-management skills must be sufficiently knowledgeable and skilled themselves to be successful. Personal experience with the disease is insufficient preparation to deliver high quality education, especially to patients ranging widely in ages, asthma severity, comorbid conditions and personal/social circumstances. Standards for asthma educators should be set in each country and supported by validated certification examinations. This approach has worked well in training and certifying diabetic educators. The advantages of certification are: teaching competency and reliable standards of quality. 
Table 1. - Likely efficacy of different methods of introducing clinical practive guidelines

\begin{tabular}{llll}
\hline $\begin{array}{l}\text { Probability of } \\
\text { being effective }\end{array}$ & Development & Dissemination & Implementation \\
\hline High & Internal & Specific educational intervention & Patient-specific reminder at consultation \\
Above average & Intermediate & Continuing medical education (CME) & Patient-specific feedback \\
Below average & External - local & Mailing targeted groups & General feedback \\
Low & External - national & Publication in a journal & General reminder \\
\hline
\end{tabular}

From a systematic review of 91 studies [169].

The role of public health policies and national campaigns and issues for high-income and low-income countries

Several countries, or regions of countries have demonstrated the benefits of public education, national campaigns and targeted regional activities; some offered by Government agencies, some by health professional collaborations and some by patient support organizations.

Mass media campaigns to increase public awareness have been evaluated in Australia [178], national asthma programmes are being evaluated in Finland, Malaysia, Norway and Peru and district asthma projects are being evaluated in the UK, USA, Canada and elsewhere.

The role of both health professional organizations and patient associations is fundamental in putting into practise the new scientific achievements, but it is essential to obtain changes in public health policies co-ordinated at the national and international level.

In low-income countries the list of the problems associated with delivery of effective care to those with asthma is often the same as in high-income countries, although the magnitude of the problems may be greater. Differing cultural perceptions may require specific education and problems with continuity of supply and availability of medicines needing to be addressed in individual country guidelines [179].

\section{Important research questions}

Communication. 1) How do researchers help both patients and health professionals communicate more effectively and use limited consultation time effectively? 2) how can it be ensured that health professionals communicate appropriate and acceptable messages? 3) the most effective method of communication needs to be determined for cultural subgroups and different age groups. The role of audiovisual materials added to the spoken and written word remain unclear as does the effectiveness of interactive multimedia and the use of e-mail and the Internet. An evaluation of the role of new methods of communication in improving health outcomes needs to be conducted.

Patient education and self-management. 1) Which selfmanagement programme is required for what type of patient?; 2) on what symptoms and objective measures (peak flow or other) should action be instituted?; 3) it will be important to determine if the same should apply to all age groups, if one setting for patient education is better than another, and the optimal timing of delivery (emergency room, initial consultation, hospitalization, etc).
For these important questions to be answered, well trained and educated health professionals are, and required how health professionals are trained to deliver self-management and who is best equipped to deliver and reinforce such training, lay educators, respiratory therapists, pharmacists, nurses or doctors, therefore needs to be established. How such teaching and education is integrated into clinical care and made widely available needs further evaluation. The problems of targeting cultural groups and those suffering socioeconomic deprivation requires careful evaluation.

The cost effectiveness of patient education and selfmanagement programmes is of increasing importance. The most cost effective way of implementing self-management programmes and their international comparability requires evaluation. This may hopefully lead to identification of the severity of asthma where the teaching of self-management is most cost effective. A large number of patients with asthma are seeking alternative complementary medicines, and whether these people are seeking the holistic approach or merely reflecting an anti-medication attitude needs to be established as well as the lessons that can be learnt and perhaps incorporated by traditional practitioners.

Lay and health professional liaison in asthma and the role of patient support organizations and asthma telephone helplines. 1) Can health care patterns and behaviour be altered in all groups of patients via community liaison initiatives?; 2) the role of patient support organizations and telephone helplines in providing selfhelp and guided support over and above usual clinical care needs to be examined, delineated and where appropriate, partnerships developed; 3) how lay educators are trained requires evaluation to ensure consistent messages are delivered; 4) the role of peer/adolescent asthmatics in the education of other young people with asthma needs to be established.

Implementation of guidelines, health professional education and models for national training. 1) Which dissemination/implementation methods for guidelines are effective in which settings?; 2) are guidelines a cost-effective tool for improving quality of care?; 3) do guidelines have a sustained effect on care and what mechanisms of reinforcement can sustain their effect through continuous implementation; 4) if education is based in primary care practices, is this cost effective?; 5) the components of educational intervention critical to success need to be clearly indentified together with the effectiveness of multiple visits compared to single visits; 6) the effectiveness of different professionals as educators (e.g. nurses, doctors, pharmacists) also requires evaluation; 7) the groups of health professionals (nurses, doctors, pharmacists, etc) 
that national training centres target for training needs to be established together with the relationship between formal educator certification and improvements in asthma outcomes; 8) the most appropriate site for delivery of training for health professionals needs to be established, for example secondary care, universities or specialist training centres; 9) in light of changes relating to nurse prescribing, the question of whether patient outcomes are equal if nurses prescribe, compared to traditional prescribing by physicians requires careful evaluation.

The role of public health policies and national campaigns and issues for low-income countries. 1) How can the role of national asthma education campaigns and other public health efforts be defined and how should they be resourced?; 2) how should the outcomes of national asthma campaigns be measured and how can effective interventions best be disseminated and diffused into the general community, into the health professional community and into target settings?; 3) how should educational, healthcare and public health policies and strategies be adapted to the needs and resources for high- and low-income countries?

\section{The message of the World Asthma Meeting}

It is relatively rare, but a real necessity, that an international, multidisciplinary team of scientists discusses and presents the state-of-the-art knowledge regarding a world-wide public health problem. That is why the 1998 World Asthma Meeting had a shared commitment. This not only led to the publication of more than 500 free communications [180], but also to the above statements on the established issues and most urgent questions with respect to the causes and care of asthma. The latter is an obvious gain, as compared to the regular, single-society meetings.

What is the take-home message of this WAM? Well, there is a tremendous amount of knowledge about the various aspects of asthma, most of which has been obtained during the past two decades. This knowledge is in the public domain, and should be readily accessible in high- as well as in low-income countries. Nevertheless, the prevalence and burden of asthma is still growing around the world. This is unacceptable, and must be a challenge for scientists, doctors, nurses, and health care officials. The WAM has shown the way forward by providing a collaborative statement that is supported by the majority of international bodies in this field.

Epidemiology. There is a need to better measure the burden of asthma by improved technology, to understand its risk factors, to evaluate interventions aimed at preventing the onset or reversing the disease. It is recommended to concentrate on cohorts of young children, migrants, occupational and adult-onset asthma, and to involve low-income countries.

Prevention. Although there is good evidence of benefits of allergen avoidance for secondary/tertiary prevention in people who have asthma, the benefits of primary prevention remain unproven. A number of randomized controlled trials of various interventions for primary pre- vention are currently underway. Progress towards effective primary prevention depends on the outcome of these trials, but will probably require further observational studies to clarify risk groups, mechanisms, and modifiable risk factors.

Pathogenesis. More information is needed on the role of genetics, immune responses and microbial flora in the onset of asthma. It has to be resolved what translates atopy into asthma, and what can be learned from intrinsic, non-IgE-mediated asthma. Other areas of interest are the role of T-cell regulation, bronchial epithelium, airways remodelling, and smooth muscle "latch" in the development and the chronicity of the disease.

Management. The value of the current classification of severity is well established, but better criteria are needed for exacerbations and referral. The present aims and cost-benefit of controlling asthma are generally accepted. However, there is huge need for international action to ensure better access to treatment. Research of cost-effectiveness of treatment is needed both in high- and low-income countries.

Education. The large benefits of good communication, patient education and self-management are well established. Research is needed to compare materials and methods, to examine the uniformity of messages and health professional training, to target sub-groups, to measure quality and effectiveness, and to promote the implementation of guidelines, training and education by public health policies and national campaigns.

It is hoped that the current research agenda will lead to substantial progress in the prevention and management of asthma in the years to come. As a first step, the WHO has announced the next World Asthma Day, on May 3rd, 2000. This should ensure the necessary communication between the experts and the lay public regarding this disease.

Secondly, the collaboration between the international societies within the World Asthma Meeting will be preserved, because the next World Asthma Meeting will be held in Chicago, USA during the summer of 2001. Hence, there are still 1-2 yrs to work on the questions outlined above.

Organised by: The European Respiratory Society (ERS; host society), The American Academy of Allergy, Asthma and Immunology (AAAAI), The American Thoracic Society (ATS), The European Academy of Allergology and Clinical Immunology (EAACI), The International Union Against Tuberculosis and Lung Diseases (IUATLD), and The Global Initiative for Asthma (GINA: including The National Heart, Lung and Blood Institute (NHLBI) and the World Health Organisation (WHO). Supported by: Associación Latinoamericana de Thórax (ALAT), Asian Pacific Society of Respirology (APSR), European Federation of Asthma and Allergy Associations (EFA), International Pediatric Respiratory and Allergy Forum (IPRAF), International Study of Asthma and Allergies in Childhood (ISAAC), International Society for Aerosols in Medicine (ISAM), and United Nations Environment Programme (UNEP). 
Working Group participants. Epidemiology and Prevention: J. Antó (Spain), A. Becker (USA), M.R. Becklake (Canada), B. Björksten (Sweden), F. de Blay (France), B. Brunekreef (The Netherlands), A.S. Buist (USA), P.G.J. Burney (UK), M. Chan-Yeung (Hong Kong), A. Custovic (UK), D.A. Enarson (France), G. Marks (Australia), F. Martinez (USA), E. von Mutius (Germany), L. Ng'an'ga (Kenya), J. Odhiambo (Kenya), N.E. Pearce (New Zealand), T.A.E. Platts-Mills (USA), D.S. Postma (The Netherlands), N. Shan Zhong (P.R. China), M.R. Sears (Canada), P. Vichyanond (Thailand), W. Vollmer (USA), U. Wahn (Germany), K. Weiss (USA), S. Weiss (USA), A. Woodcock (UK), A.J. Woolcock (Australia). Pathogenesis: B. Björksten (Sweden), E.R. Bleecker (USA), B. Bochner (USA), S. Bonin (Italy), L-Ph. Boulet (Canada), J. Bousquet (France), W.W. Busse (USA), Th. Casale (USA), W. Cookson (UK), L.M. Fabbri (Italy), A.J. Frew (UK), P. Howarth (UK), M. Humbert (France), P.K. Jeffery (UK), D. Olivieri (Italy), L.J. Rosenwasser (USA), H-W. Simon (Switzerland), A.J. Szczeklik (Poland), M Vignola (Italy), J.O. Warner (UK), H. Yssel (France). Management: N. Ait-Khaled (France), C.E. BaenaCagnani (Argentina), M. Bartal (Morocco), W.W. Busse (USA), Y-Z. Chen (P.R. China), E. Dagli (Turkey), P. Diaz (Chile), D.A. Enarson (France), M. Greenblatt (South Africa), M. Hadjarto (Indonesia), B Keita (Côte d' Ivoire), R. Naidu (Barbados), H.E. Neffen (Argentina), P.M. O'Byrne (Canada), K. Ohta (Japan), R.A. Pauwels (Belgium), S. Pedersen (Sweden), O. Sow (Guinée), N. Tudoric (Croatia), M. Yousser (Syria), N. Zidouni (Algeria). Education: G.R Barnes (UK), R. Beasley (New Zealand), N.M. Clark (USA), T.J.H. Clarke (UK), D. Evans (USA), M. Franchi (Italy), Ch. Griffiths (UK), S.L. Hill (UK), S. Janson (USA), Ch. Jenkins (Australia), S. Jeyaindran (Malaysia), J.J. Klein (The Netherlands), A. Lahdensuo (Finland), Ph. Madge (UK), L.M. Osman (UK), M.R. Partridge (UK), A. Pearsson (UK), G.S. Rachelefsky (USA), E.M.A.L. Rameckers (The Netherlands), R.B. Singh (India), V.S. Taggart (USA), R. Theodorakis (USA), J. van der Palen (The Netherlands), H. van der Velden (The Netherlands), S. Wilson (USA), M. Worstell (USA)

\section{References}

1. Burney PGJ, Luczynska C, Chinn S, Jarvis D, for the European Community Respiratory Health Survey. The European Community Respiratory Health Survey. Eur Respir J 1994; 7: 954-960.

2. Chinn S, Burney P, Jarvis D, Luczynska C, on behalf of the European Community Respiratory Health Survey (ECRHS). Variation in bronchial responsiveness in the European Community Respiratory Health Survey (ECRHS). Eur Respir J 1997; 10: 2495-2501.

3. Jarvis D, Chinn S, Sterne J, Luczynska C, Burney P, on behalf of the European Community Respiratory Health Survey. The association of respiratory symptoms and lung function with the use of gas cooking. Eur Respir J 1998; 11: 651-658.

4. Burney P, Malmberg E, Chinn S, et al. The distribution of total and specific serum IgE in the European Community Respiratory Health Survey. J Allergy Clin Immunol 1997; 99: 314-322.

5. International Study of Asthma and Allergies in Childhood (ISAAC) Steering Committee. Worldwide variations in the prevalence of asthma symptoms: the International
Study of Asthma and Allergies in Childhood (ISAAC). Eur Respir J 1998; 12: 315-335.

6. International Study of Asthma and Allergies in Childhood (ISAAC) Steering Committee. Worldwide variation in the prevalence of symptoms of asthma, allergic rhinoconjunctivitis, and atopic eczema: ISAAC. Lancet 1998; 351: 1225-1232.

7. Leung RC, Carlin JB, Burdon JGW, Czarny D. Asthma, allergy and atopy in Asian immigrants in Melbourne. Med $J$ Aust 1994; 161: 418-425.

8. Arshad SH, Matthews S, Gant C, Hide DW. Effect of allergen avoidance on development of allergic disorders in infancy. Lancet 1992; 339: 1493-1497.

9. Hide DW, Matthews S, Matthews L, et al. Effect of allergen avoidance in infancy on allergic manifestations at age two years. J Allergy Clin Immunol 1994; 93: 842846.

10. Hide DW, Matthews S, Tariq S, Arshad SH. Allergen avoidance in infancy and allergy at 4 yrs of age. Allergy 1996; 51: 89-93.

11. Nishioka K, Yaseuda H, Saito H. Preventive effect of bedding encasement with microfine fibers on mite sensitization. J Allergy Clin Immunol 1998; 101: 28-32.

12. Frederick JM, Gill LS, Warner JO, Colwell BM, Warner JA. Allergen avoidance in the homes of asthmatic parents during pregnancy. J Allergy Clin Immunol 1998; 101: S26.

13. Chan-Yeung M, Ferguson A, Dimich-Ward H, Watson W, Becker A, Manfreda J. Primary prevention of asthma and other allergic disorders: a multifaceted intervention in high risk infants. Am J Respir Crit Care Med 1998; 157: A12.

14. Custovic A, Simpson BM, Simpson A, Woodcock A. Low allergen environment can be achieved and maintained throughout pregnancy and in early life. J Allergy Clin Immunol 1998; 101: S81.

15. Kerrebijn KF. Endogenous factors in childhood CNSLD: methodological aspects in population studies. In: One N, van der Lende K, eds. Bronchitis III. The Netherlands: Royal Vangoreum Assen, 1970; pp. 33-48.

16. Platts-Mills TAE, Vervolet D, Thomas WR, Aalberse RC, Chapman MD. Indoor allergens and asthma. Third International Workshop, Cuenca, Spain. J Allergy Clin Immunol 1997; 100: S1-S24.

17. Platts-Mills TAE, Tovey ER, Mitchell EB, Moszora H, Nock P, Wilkins SR. Reduction of bronchial hyperreactivity during prolonged allergen avoidance. Lancet 1982 ; 2: 675-677.

18. Boner AL, Niero E, Antolini I, Valletta EA, Gaburro D. Pulmonary function and bronchial hyperreactivity in asthmatic children with house dust mite allergy during prolonged stay in the Italian Alps (Misurina 1765m). Ann Allergy 1985; 54: 42-45.

19. Halken S, Niklassen U, Hansen LG, et al. Encasing mattresses in children with asthma and house duste mite allergy. J Allergy Clin Immunol 1997; 99: S320.

20. Carswell F, Birmingham K, Oliver J, Crewes A, Weeks J. The respiratory effects of reduction of mite allergen in the bedrooms of asthmatic children - a double blind controlled trial. Clin Exp Allergy 1996; 26: 386-396.

21. Ehnert B, Lau-Schadendorf S, Weber A, Buettner P, Schou C, Wahn U. Reducing domestic exposure to dust mite allergen reduces bronchial hyperreactivity in sensitive children with asthma. J Allergy Clin Immunol 1992; 90: 135-138.

22. Murray AB, Ferguson AC. Dust-free bedrooms in the treatment of asthmatic children with house dust or house dust mite allergy: a controlled trial. Pediatrics 1983; 71: 418-422.

23. Walshaw MJ, Evans CC. Allergen avoidance in house dust mite sensitive adult asthma. Q J Med 1986; 58: 199 215 . 
24. Vaughan JW, McLaughlin TE, Perzanowski MS, PlattsMills TAE. Evaluation of materials used for bedding encasement: effect of pore size in blocking cat and dust mite allergen. J Allergy Clin Immunol 1999; 103: 227236.

25. Avner DB, Perzanowski MS, Platts-Mills TAE, Woodfolk JA. Evaluation of different techniques for washing cats: quantitation of allergen removed from the cat and the effect on airborne Feld I. J Allergy Clin Immunol 1997; 100: $307-312$

26. De Blay F, Chapman MD, Platts-Mills TAE. Airborne cat allergen (Feld I). Environmental control with cat in situ. Am Rev Respir Dis 1991; 143: 1334-1339.

27. Martinez FD. Maternal risk factors in asthma. Ciba Found Symp 1997; 206: 233-239.

28. Holt PG, Yabuhara A, Prescott S, et al. Allergen recognition in the origin of asthma. Ciba Found Symp 1997; 206: 35-49.

29. Prescott SL, Macaubas C, Holt BJ, et al. Transplacental priming of the human immune system to environmental allergens: universal skewing of initial T-cell responses toward the Th2 cytokine profile. J Immunol 1998; 160: 4730-4737.

30. Prescott S, Macaubas C, Smallcombe T, Holt B, Sly P, Holt P. Development of allergen-specific T-cell memory in atopic and normal children. Lancet 1999; 353: 196-200.

31. Jones C, Warner J, Warner J. Foetal swallowing of IgE. Lancet 1998; 351: 1859.

32. Warner JA, Jones AC, Miles EA, Colwell BM, Warner JO. Prenatal origins of asthma and allergy. Ciba Found Symp 1997; 206: 220-228.

33. Shaheen SO, Aaby P, Hall AJ, et al. Measles and atopy in Guinea-Bissau. Lancet 1996; 347: 1792-1796.

34. Erb KJ, Holloway JW, Sobeck A, Moll H, Le-Gros G. Infection of mice with Mycobacterium bovis-Bacillus Calmette-Guerin (BCG) suppresses allergen-induced airway eosinophilia. J Exp Med 1998; 187: 561-569.

35. Björksten B. Environmental risk factors for atopy. Clin Rev Allergy Immunol 1997; 15: 125-143.

36. Burr ML, Merrett TG, Dunstan FD, Maguire MJ. The development of allergy in high-risk children. Clin Exp Allergy 1997; 27: 1247-1253.

37. ETAC $(\mathbb{R}$-study-group. Allergic factors associated with the development of asthma and the influence of cetrizine in a double-blind, randomized, placebo-controlled trial: First results of ETACR. Ped Allergy Immunol 1998; 9: $116-124$

38. Holloway JW, Beghé B, Holgate ST. The genetic basis of atopic asthma. Clin Exp Allergy 1999; 29: 1023-1032.

39. Bleecker ER, Postma DS, Meyers DA. Genetic susceptibility to asthma in a changing environment. Ciba Found Symp 1997; 206: 90-99.

40. Moffatt MF, Cookson WO. Linkage and candidate gene studies in asthma. Am J Respir Crit Care Med 1997; 156: S110-S112.

41. Sporik R, Holgate ST, Platts-Mills TA, Cogswell JJ. Exposure to house-dust mite allergen (Der p I) and the development of asthma in childhood. A prospective study. N Engl J Med 1990; 323: 502-507.

42. Martinez FD, Wright AL, Taussig LM, Holberg CJ, Halonen M, Morgan WJ. Asthma and wheezing in the first six years of life. The Group Health Medical Associates. $N$ Engl J Med 1995; 332: 133-138.

43. Folkerts G, Busse WW, Nijkamp FP, Sorkness R, Gern JE. Virus-induced airway hyperresponsiveness and asthma. Am J Respir Crit Care Med 1998; 157: 1708-1720.

44. Calhoun WJ, Dick EC, Schwartz LB, Busse WW. A common cold virus, rhinovirus 16 , potentiates airway inflammation after segmental antigen bronchoprovocation in allergic subjects. J Clin Invest 1994; 94: 2200-2208.
45. Strachan DP, Harkins LS, Johnston ID, Anderson HR. Childhood antecedents of allergic sensitization in young British adults. J Allergy Clin Immunol 1997; 99: 6-12.

46. Bousquet J, Chanez P, Lacoste JY, et al. Eosinophilic inflammation in asthma. N Engl J Med 1990; 323: 10331039.

47. Robinson DS, Hamid Q, Ying S, et al. Predominant TH2like bronchoalveolar T-lymphocyte population in atopic asthma. N Engl J Med 1992; 326: 298-304.

48. Lamkhioued B, Renzi PM, Abi-Younes S, et al. Increased expression of eotaxin in bronchoalveolar lavage and airways of asthmatics contributes to the chemotaxis of eosinophils to the site of inflammation. J Immunol 1997; 159: 4593-4601.

49. Humbert M, Ying S, Corrigan C, et al. Bronchial mucosal expression of the genes encoding chemokines RANTES and MCP-3 in symptomatic atopic and nonatopic asthmatics: relationship to the eosinophil-active cytokines interleukin (IL)-5, granulocyte macrophage-colony-stimulating factor, and IL-3. Am J Respir Cell Mol Biol 1997; 16: 1-8.

50. Humbert M, Durham SR, Kimmitt P, et al. Elevated expression of messenger ribonucleic acid encoding IL-13 in the bronchial mucosa of atopic and nonatopic subjects with asthma. J Allergy Clin Immunol 1997; 99: 657-665.

51. Fabbri LM, Maestrelli P, Saetta M, Mapp CE. Airway inflammation during late asthmatic reactions induced by toluene diisocyanate. Am Rev Respir Dis 1991; 143: S37S38.

52. Saetta M, Di-Stefano A, Maestrelli P, et al. Airway mucosal inflammation in occupational asthma induced by toluene diisocyanate. Am Rev Respir Dis 1992; 145: 160-168.

53. Di-Stefano A, Saetta M, Maestrelli P, et al. Mast cells in the airway mucosa and rapid development of occupational asthma induced by toluene diisocyanate. Am Rev Respir Dis 1993; 147: 1005-1009.

54. Frew A, Chan H, Dryden P, Salari H, Lam S, Chan-Yeung M. Immunologic studies of the mechanisms of occupational asthma caused by western red cedar. J Allergy Clin Immunol 1993; 92: 466-478.

55. Saetta M, Maestrelli P, Di-Stefano A, et al. Effect of cessation of exposure to toluene diisocyanate (TDI) on bronchial mucosa of subjects with TDI-induced asthma. Am Rev Respir Dis 1992; 145: 169-174.

56. Boulet LP, Boutet M, Laviolette M, et al. Airway inflammation after removal from the causal agent in occupational asthma due to high and low molecular weight agents. Eur Respir J 1994; 7: 1567-1575.

57. Chung KF, Barnes PJ. Cytokines in asthma. Thorax 1999; 54: 825-857.

58. Kay AB. T-cells as orchestrators of the asthmatic response. Ciba Found Symp 1997; 206: 56-67.

59. Krug N, Madden J, Redington AE, et al. T-cell cytokine profile evaluated at the single cell level in BAL and blood in allergic asthma. Am J Respir Cell Mol Biol 1996; 14: 319-326.

60. Ying S, Humbert M, Barkans J, et al. Expression of IL-4 and IL-5 mRNA and protein product by CD4+ and CD8+ T-cells, eosinophils, and mast cells in bronchial biopsies obtained from atopic and nonatopic (intrinsic) asthmatics. J Immunol 1997; 158: 3539-3544.

61. Borish L, Rosenwasser L. TH1/TH2 lymphocytes: doubt some more. J Allergy Clin Immunol 1997; 99: 161-164.

62. Krug N, Frew AJ. The Th2 cell in asthma: initial expectations yet to be realised. Clin Exp Allergy 1997; 27: 142150 .

63. Abbas AK, Murphy KM, Sher A. Functional diversity of helper T lymphocytes. Nature 1996; 383: 787-793.

64. Santamaria-Babi LF, Picker LJ, Perez-Soler MT, et al. Circulating allergen-reactive T-cells from patients with 
atopic dermatitis and allergic contact dermatitis express the skin-selective homing receptor, the cutaneous lymphocyte-associated antigen. J Exp Med 1995; 181: 19351940.

65. Butcher EC, Picker LJ. Lymphocyte homing and homeostasis. Science 1996; 272: 60-66.

66. Baggiolini M, Dewald M, Moser B. Human chemokines: an update. Annu Rev Immunol 1997; 15: 675-705.

67. Jourdan P, Abbal C, Nora N, et al. IL-4 induces functional cell-surface expression of CXCR4 on human T-cells. $J$ Immunol 1998; 160: 4153-4157.

68. Sallusto F, Lanzavecchia A, Mackay C. Chemokines and chemokine receptors in T-cell priming and Th1/Th2 responses. Immunol Today 1998; 19: 568-574.

69. Kemeny DM, Noble A, Holmes BJ, Diaz-Sanchez D, Lee $\mathrm{TH}$. The role of CD8+ T-cells in immunoglobulin E regulation. Allergy 1995; 50: 9-14.

70. Lambrecht BN, Salomon B, Klatzmann D, Pauwels RA Dendritic cells are required for the development of chronic eosinophilic airway inflammation in response to in haled antigen in sensitized mice. J Immunol 1998; 160 : 4090-4097.

71. Schwiebert LM, Stellato C, Schleimer RP. The epithelium as a target of glucocorticoid action in the treatment of asthma. Am J Respir Crit Care Med 1996; 154: S19-S20.

72. Campbell AM, Chanez P, Vignola AM, et al. Functional characteristics of bronchial epithelium obtained by brushing from asthmatic and normal subjects. Am Rev Respir Dis 1993; 147: 529-534.

73. Lee JJ, McGarry MP, Farmer SC, et al. Interleukin-5 expression in the lung epithelium of transgenic mice leads to pulmonary changes pathognomonic of asthma. J Exp Med 1997; 185: 2143-2156.

74. Humbles AA, Conroy DM, Marleau S, et al. Kinetics of eotaxin generation and its relationship to eosinophil accumulation in allergic airways disease: analysis in a guinea pig model in vivo. J Exp Med 1997; 186: 601-612.

75. Sousa AR, Poston RN, Lane SJ, Nakhosteen JA, Lee TH. Detection of GM-CSF in asthmatic bronchial epithelium and decrease by inhaled corticosteroids. Am Rev Respir Dis 1993; 147: 1557-1561.

76. Vignola AM, Chanez P, Chiappara G, et al. Transforming growth factor-beta expression in mucosal biopsies in asthma and chronic bronchitis. Am J Respir Crit Care Med 1997; 156: 591-599.

77. Hamid Q, Springall DR, Riveros-Moreno V, et al. Induction of nitric oxide synthase in asthma. Lancet 1993; 342 : $1510-1513$.

78. Springall DR, Howarth PH, Counihan H, Djukanovic R, Holgate ST, Polak JM. Endothelin immunoreactivity of airway epithelium in asthmatic patients. Lancet 1991; 337: 697-701.

79. Finsnes F, Skjonsberg OH, Tonnessen T, Naess O, Lyberg T, Christensen G. Endothelin production and effects of endothelin antagonism during experimental airway inflammation. Am J Respir Crit Care Med 1997; 155: 14041412

80. Sont JK, van-Krieken JH, van-Klink HC, et al. Enhanced expression of neutral endopeptidase (NEP) in airway epithelium in biopsies from steroid-versus nonsteroid-treated patients with atopic asthma. Am J Respir Cell Mol Biol 1997; 16: 549-556.

81. Vignola AM, Campbell AM, Chanez P, et al. HLA-DR and ICAM-1 expression on bronchial epithelial cells in asthma and chronic bronchitis. Am Rev Respir Dis 1993; 148: 689-694

82. Lackie PM, Baker JE, Gunthert U, Holgate ST. Expression of CD44 isoforms is increased in the airway epithelium of asthmatic subjects. Am J Respir Cell Mol Biol 1997; 16: 14-22.
83. Persson CG, Erjefalt JS, Andersson M, et al. Epithelium, microcirculation, and eosinophils - new aspects of the allergic airway in vivo. Allergy 1997; 52: 241-255.

84. Bousquet J, Chanez P, Lacoste JY, et al. Asthma: a disease remodeling the airways? Allergy 1992; 47: 3-11.

85. Roche WR, Beasley R, Williams JH, Holgate ST. Subepithelial fibrosis in the bronchi of asthmatics. Lancet 1989; 1: 520-524.

86. Laitinen A, Altraja A, Kampe M, Linden M, Virtanen I, Laitinen LA. Tenascin is increased in airway basement membrane of asthmatics and decreased by an inhaled steroid. Am J Respir Crit Care Med 1997; 156: 951-958.

87. Altraja A, Laitinen A, Virtanen I, et al. Expression of laminins in the airways in various types of asthmatic patients: a morphometric study. Am J Respir Cell Mol Biol 1996; 15: 482-488.

88. Chetta A, Foresi A, Del-Donno M, Bertorelli G, Pesci A, Olivieri D. Airways remodeling is a distinctive feature of asthma and is related to severity of disease. Chest 1997; 111: 852-857.

89. Boulet LP, Laviolette M, Turcotte H, et al. Bronchial subepithelial fibrosis correlates with airway responsiveness to methacholine. Chest 1997; 112: 45-52.

90. Hoshino M, Nakamura Y, Sim JJ. Expression of growth factors and remodelling of the airway wall in bronchial asthma. Thorax 1998; 53: 21-27.

91. Djukanovic R, Lai CK, Wilson JW, et al. Bronchial mucosal manifestations of atopy: a comparison of markers of inflammation between atopic asthmatics, atopic nonasthmatics and healthy controls. Eur Respir J 1992; 5: 538544.

92. Minshall EM, Leung DY, Martin RJ, et al. Eosinophilassociated TGF-beta1 mRNA expression and airways fibrosis in bronchial asthma. Am J Respir Cell Mol Biol 1997; 17: 326-333.

93. Paganin F, Seneterre E, Chanez P, et al. Computed tomography of the lungs in asthma: influence of disease severity and etiology. Am J Respir Crit Care Med 1996; 153: 110-114.

94. Chakir J, Laviolette M, Boutet M, Laliberte R, Dube J, Boulet LP. Lower airways remodeling in nonasthmatic subjects with allergic rhinitis. Lab Invest 1996; 75: 735-744.

95. Brewster CE, Howarth PH, Djukanovic R, Wilson J, Holgate ST, Roche WR. Myofibroblasts and subepithelial fibrosis in bronchial asthma. Am J Respir Cell Mol Biol 1990; 3: 507-511.

96. Hoshino M, Nakamura Y, Sim J, Shimojo J, Isogai S. Bronchial subepithelial fibrosis and expression of matrix metalloproteinase-9 in asthmatic airway inflamation. $J$ Allergy Clin Immunol 1998; 102: 783-788.

97. Bousquet J, Lacoste JY, Chanez P, Vic P, Godard P, Michel FB. Bronchial elastic fibers in normal subjects and asthmatic patients. Am J Respir Crit Care Med 1996; 153: 1648-1654.

98. Vignola AM, Bonanno A, Mirabella A, et al. Increased levels of elastase and alpha1-antitrypsin in sputum of asthmatic patients. Am J Respir Crit Care Med 1998; 157 : 505-511.

99. Godfrey RW, Lorimer S, Majumdar S, et al. Airway and lung elastic fibre is not reduced in asthma nor in asthmatics following corticosteroid treatment. Eur Respir $J$ 1995; 8: 922-927.

100. Saetta M, Maestrelli P, Turato G, et al. Airway wall remodeling after cessation of exposure to isocyanates in sensitized asthmatic subjects. Am J Respir Crit Care Med 1995; 151: 489-494.

101. Saetta M, Di-Stefano A, Rosina C, Thiene G, Fabbri LM. Quantitative structural analysis of peripheral airways and arteries in sudden fatal asthma. Am Rev Respir Dis 1991; 143: $138-143$. 
102. Carroll N, Elliot J, Morton A, James A. The structure of large and small airways in nonfatal and fatal asthma. Am Rev Respir Dis 1993; 147: 405-410.

103. Lambert RK, Wiggs BR, Kuwano K, Hogg JC, Pare PD. Functional significance of increased airway smooth muscle in asthma and COPD. J Appl Physiol 1993; 74: 27712781.

104. Redington AE, Madden J, Frew AJ, et al. Transforming growth factor-beta 1 in asthma. Measurement in bronchoalveolar lavage fluid. Am J Respir Crit Care Med 1997; 156: 642-647.

105. Amishima M, Munakata M, Nasuhara Y, et al. Expression of epidermal growth factor and epidermal growth factor receptor immunoreactivity in the asthmatic human airway. Am J Respir Crit Care Med 1998; 157: 1907-1912.

106. Simon HU, Yousefi S, Schranz C, Schapowal A, Bachert C, Blaser K. Direct demonstration of delayed eosinophil apoptosis as a mechanism causing tissue eosinophilia. $J$ Immunol 1997; 158: 3902-3908.

107. Druilhe A, Wallaert B, Tsicopoulos A, et al. Apoptosis, proliferation, and expression of Bcl-2, Fas, and Fas-ligand in bronchial biopsies from asthmatics. Am J Respir Cell Biol Mol 1998; 19: 747-757.

108. Fredberg J, Inouye DS, Mijailovich SM, Butler JP. Pertubed equilibrium of myosin-binding in airway smooth muscle and its implications in bronchospasm. Am J Respir Crit Care Med 1999; 159: 959-967.

109. Global Initiative for Asthma. Pocket guide for asthma management and prevention. Washingon: National Heart, Lung and Blood Institute, 1998.

110. Global Initiative for Asthma. Global Strategy for Asthma Management and Prevention. 1995; Publ. 95-3659, 1176. Washington: National Heart, Lung and Blood Institute, National Institutes of Health.

111. Warner JO, Naspitz CK, Cropp GJA. Third International pediatric consensus statement on the management of childhood asthma. Pediatr Pulmonol 1998; 25: 1-7.

112. Hargreave FE, Dolovich J, Newhouse MT. The assessment and treatment of asthma: a conference report. $\mathrm{J} \mathrm{Al}$ lergy Clin Immunol 1990; 85: 1098-1111.

113. British Thoracic Society. The British Guidelines on Asthma Management. Thorax 1997; 52: S1-S21.

114. Management of Asthma. Bethesda: National Heart, Lung and Blood Institute; National Institutes of Health, 1997.

115. Management of asthma in adults. Guide for low-income countries. International Union Against Tuberculosis and Lung Diseases. Ac̈t-Khaled N, Enarson DA, eds. Frankfurt am Main, Moscow, Sennwald, Wien; pmi-VerlGruppe, 1996

116. Stewart MA. Effective physician-patient communication and health outcomes -a review. Can Med Assoc J 1995; 142: 1423-1433.

117. Roter DL, Hall JA, Kern DE, Barker LR, Cole KA, Roca RP. Improving physicians interviewing skills and reducing patients emotional distress: a randomised clinical trial. Arch Intern Med 1995; 55: 877-884.

118. Clark NM, Gong M, Schods MA, et al. Impact of education for physicians and patient outcomes. Pediatrics 1998; 101: 831-836.

119. Becker MH. Theoretical models of adherence and strategies for improving adherence. In: SA Scumaker, EG Schron, JK Ockene, eds. Handbook of Health Behaviour Change. New York, Springer, 1990.

120. Clark NM, Nothwehr F, Gong M, Evans D, Maiman LA, Hurwitz ME, Roloff D, Mellino RB. Physician-patient partnership in managing chronic illness. Acad Med 1995; 70: 957-959.

121. Suchman AL, Markakis K, Beckman HB, Frankel R. A model of empathic communication in the medical interview. JAMA 1997; 277: 678-682.
122. Ong LM, de Haes JC, Hoos AM, Lammes FB. Doctorpatient communication: a review of the literature. Soc Sci Med 1995; 40: 903-918.

123. Lewis CE, Rachelefsky G, Lewis MA, de la Sota A, Kaplan M. A randomised trial of A.C.T. (Asthma Care Training) for Kids. J Ped 1984; 74: 478-482.

124. Muhlhausen I, Richter B, Kraut D, Weske G, Worth H, Berger M. Evaluation of a structured treatment and teaching program on asthma. J Intern Med 1991; 230: $157-164$.

125. Osman L. Better information materials: how to provide what patients really want. The Asthma Journal 1998; 3: $162-165$.

126. American Lung Association Working Group. Standards for Comprehensive Asthma Education Programs. New York; American Lung Association, 1998.

127. Allen RM, Jones M, Oldenburg B. Randomised trial of asthma self management programme for adults. Thorax 1995; 50: 731-738.

128. Clark NM, Feldman CH, Evans D, Levison MJ, Wasilewski Y, Mellins RB. The impact of health education on frequency and cost of health care use by low income children with asthma. J Allergy Clin Immunol 1986; 78 : 108-115.

129. Hilton S, Anderson H, Sibbalrd B, Freeling P. Survey. Controlled evaluation of the effects patient education on asthma morbidity in general practice. Lancet 1986; 1:2629.

130. Kotses H, Bernstein I, Bernstein D, Reynolds R, Korbee L, Wigal J, Ganson E, Stout C, Creer TL. A self management program for adult asthma. Part I: Development and evaluation. J Allergy Clin Immunol 1995; 95: 529540.

131. Jenkinson D, Davidson J, Jones S, Hawtin P. Comparison of effects of a self management booklet and audiocassette for patients with asthma. $\mathrm{Br}$ Med $J$ 1988; 297: 267-270.

132. Snyder SE, Winder JA, Creer TJ. Development and evaluation of an adult asthma self management program: wheezers Anonymous. J Asthma 1987; 24: 153-158.

133. Ringsberg KVC, Wiflund I, Wilhelmsen L. Education of adult patients at an "asthma school". Effects on quality of life, knowledge and need for nursing. Eur Respir J 1990; 3: 33-37.

134. Garrett J, Fenwick JM, Taylor G, Mitchell E, Stewart J, Rea H. Prospective controlled evaluation of the effect of a community based asthma education centre in a multiracial working class neighbourhood. Thorax 1994; 49: 976-983.

135. Wilson SR, Scamagas P, Grado J, et al. The Fresno Asthma Project: a model intervention to control asthma in multiethnic low income inner city communitites. Health Education and Behavior 1998; 25: 790-798.

136. Bailey W, Richards JJ, Brooks C, Soong S, Windsor R, Manzella B. A randomised trail to improve self management practices of adults with asthma. Arch Intern Med 1990; 150: 1664-1668.

137. Huss K, Salerno M, Huss RW. Computer assisted reinforcement of instructions: effects on adherence in adult atopic asthmatics. Res Nurs Health 1991; 14: 259-267.

138. Osman LM, Abdalla MI, Beattie JA, et al. Reducing hospital admission through computer supported education for asthma patients. Grampian Asthma Study of integrated care (GRASSIC). Br Med J 1994; 308: 568-571.

139. Charlton I, Charlton G, Broomfield J, Mullee MA. Randomised controlled trial. Evaluation of peak flow an symptoms only self management plans for control of asthma in general practice. $B r$ Med $J$ 1990; 301: 13551359.

140. Charlton I, Antoniou AG, Atkinson J, et al. Asthma at the interface: bridging the gap between general practice and a 
district general hospital. Arch Dis Child 1994; 70: 313318.

141. Maiman LA, Green LW, Gibson G, MacKenzie EJ. Education for self treatment by adult asthmatics. JAMA 1979; 241: 1919-1922.

142. Bolton MB, Tilley BC, Kuder J, et al. The cost and effectiveness of an education program for adults who have asthma. J Gen Intern Med 1991; 6: 401-417.

143. Yoon R, McKenzie D, Bauman A, Miles D. Controlled trial evaluation of an asthma education programme for adults. Thorax 1993; 48: 1110-1116.

144. Windsor RA, Bailey WC, Richards JM Jr, Manzella B, Soong SJ, Brooks M. Evaluation of the efficacy and cost effectiveness of health education methods to increase medication adherence among adults with asthma. Am J Pub Health 1990; 80: 1519-1521.

145. Gibson PG. The effects of self management education and regular medical review on health outcomes in adults with asthma. Cochrane Database of Systemic Reviews (issue 4). Oxford, Update software 1998.

146. Evans D, Mellins R, Loback K, et al. Improving care for minority children with asthma: professional education in public health clinics. Pediatrics 1997; 99: 157-164.

147. Madge P, McColl JH, Paton JY. Impact of a nurse-led home management training programme in children admitted to hospital with acute asthma: a randomised controlled trial. Thorax 1997; 52: 223-228.

148. Rachelefsky GS. Review of asthma self management programs. J Allergy Clin Immunol 1987; 80: 506-511.

149. Osman L, Friend JAR, Legge JS, Douglas G. Successful avoidance of hospital readmission in acute asthma. Eur Respir J 1994; 7: 13s.

150. Lahdensuo A, Haahtela T, Herrala J, et al. Randomised comparison of guided self management and traditional treatment of asthma over one year. BMJ 1996; 312: 748752.

151. Ignacio-Garcia JM, Gonzalez-Santos P. Asthma self management education program by home monitoring of peak expiratory flow. Am J Respir Crit Care Med 1995; 151: 353-359.

152. D'Souza WJ, Karu HTe, Fox C, et al. Long term reduction in asthma morbidity following an asthma self management programme. Eur Respir J 1998; 11: 611-616.

153. Fisher EB, Sussman LK, Arflen C, et al. Targeting high risk groups: neighbourhood organisation for pediatric asthma management in the neighbourhood Asthma Coalition. Chest 1994; 106: 248S-259S.

154. Butz AM, Malveaux FJ, Eggleston P, et al. Use of community health workers with inner-city children who have asthma. Clin Ped 1994; 33: 135-141.

155. Beasley R, D'Souza W, Te Karu H, et al. Trial of an asthma action plan in the Maori community of the Wairarapa. N Z Med 1993; 106: 336-338.

156. Evans D, Clark N, Feldman CH, et al. A school health education program for children with asthma aged 8 to 11 years. Health Educ $Q$ 1987; 14: 267-279.

157. Parcel GS, Nader PR, Teirnan K. A health education program for children with asthma. J Dev Behav Paediatr 1980; 1: 128-132.

158. Gibson PG, Shah S, Momoon HA. Peer-led Asthma Education for Adolescents: Impact Evaluation. J Adol Health 1998; 22: 66-72.

159. Trautner C, Richter B, Berger M. Cost effectiveness of a structured treatment and teaching program on asthma. Eur Respir J 1993; 6: 1485-1491.

160. Taitel MS, Kotses H, Bernstein DI, et al. A self management program for adult asthma. Part II: cost-benefit analysis. J Allergy Clin Immunol 1995; 95: 672-676.
161. Neri M, Migliori GB, Spanevello A, et al. Economic analysis of two structured treatment and teaching programs on asthma. Allergy 1996; 51: 313-319.

162. Lahdensuo A, Haahtela T, Herrala J, et al. Randomised comparison of cost effectiveness of guided self management and traditional treatment of asthma in Finland. BMJ 1998; 316: 1138-1139.

163. Stout JW, White LC, Rogers LT, et al. The asthma outreach project; a promising approach to comprehensive asthma management. J Asthma 1998; 35: 119-127.

164. Wilson SR, Scamagas P, German DF, et al. A controlled trial of two forms of self management education for adults with asthma. Am J Med 1993; 94: 564-576.

165. GINA newsletter; ed. office: MCR Inc. 8316 86th Ave NW, Gig Harbour WA 98332; vol 4 August 1998.

166. Legoretta AP, Christian-Herman J, O'Connor RD, Hasan MM, Evans R, Leung KM. Compliance with national asthma management guidelines and speciality care: a health maintenance organization experience. Arch Int Med 1998; 158: 457-464.

167. Hartert TV, Windom HH, Peebles RSJr, Freidhoff LR, Togias A. Inadequate outpatient medical therapy for patients with asthma admitted to two urban hospitals. Am J Med 1996; 100: 386-394.

168. Lang DM, Sherman MS, Polansky M. Guidelines and realities of asthma management. The Philadelphia Story. Arch Int Med 1997; 157: 1193-1200.

169. Grimshaw JM, Russell IT. Effect of clinical guidelines on medical practice: a systematic review of rigorous evaluations. Lancet 1993; 342: 1317-1322.

170. Worrall G, Chaulk P, Freake D. The effects of clinical practice guidelines on patient outcomes in primary care: a systematic review. Can Med Assoc J 1997; 156: 17051712.

171. Wensing M, Grol R. Single and combined strategies for implementing changes in parimary care: a literature review. Int J Quality in Health Care 1994; 6: 115-132.

172. Thomson MA, Oxman AD, Davis DA, Haynes RB, Freemantle N, Harvey EL. Outreach visits to improve health professional practice and health care outcomes (Cochrane Review). In: The Cochrane Library. 3rd Edn. Oxford Update Software 1998.

173. Davis DA, Thomson MA, Oxman AD, Haynes RB. Changing physician performance. A systematic review of the effect of continuing medical education strategies. JAMA 1995; 274: 700-705.

174. Dickinson J, Hutton S, Atkin A. Implementing the BTS Guidelines. The effect of a nurse run asthma clinic on prescribed treatment in a North Lincolnshire general practice. Respir Med 1997; 91: 634-640.

175. Patterson M. Inhaled steroids, theophyllines and salmeterol: a comparison of morbidity data from 2,375 patients and the prescribing habits of their physicians in primary care. Am J Respir Crit Care Med 1997; 155(4): A891.

176. Neville RG, Hoskins G, Smith B, Clark RA. Observations on the structure, process and clinical outcomes of asthma care in general practice. Br J Gen Prac 1997; 46: 583587.

177. Osman L. The patient perspective. What should a new antiasthma agent provide? Drugs 1996; 52 (Suppl 6):29-35.

178. Comino E, Bauman A, Mitchel CA, et al. The Australian National Asthma Campaign: effects of public education activities based on mass media. Am J Prev Med 1997; 13: 251-256.

179. Watson JP, Lewis LA. Is asthma treatment affordable in developing countries? Thorax 1997; 52: 605.

180. The 1998 World Asthma Meeting. Abstracts. Eur Respir J 1999; 12 (Suppl. 29): 1s-100s. 